\title{
عظمة الله في خلق الانسان
}

\section{Doi: $10.23918 /$ ilic2020.46}

م.م. مشعل محمود حسين

ثانوية الامام البخاري الاسلامية/نينوى مدين

mshmh1979@yahoo.com

\section{المقدمة}

الحمد لله العلي العظيم العزيز الحكيم الذي فطرنا باقتداره وطورنا باختياره وصورنا في أحسن تقويم ومنَّ علينا بالعقل

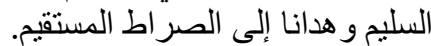

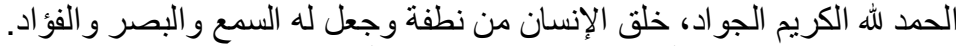

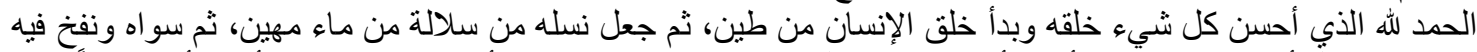

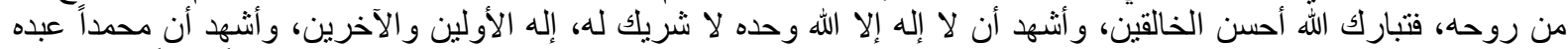
ورسوله سيد المرسلين و إمام المتقين، اللهم صل على محمد و على آله وصحبه و التابعين لهم أجمعين، وسلم تسليماً كثير ال.

أما بعد: فالله سبحانه وتعالى دلنا على وحدانيته بالآيات البينات، ووضح لنا معرفته بالحجج و البر اهين القاطعات، أحسن بقدرته

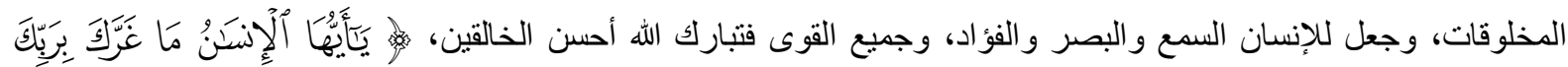

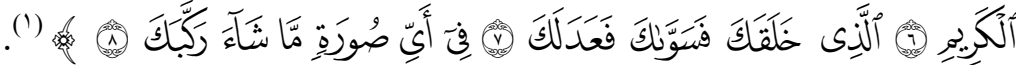
تتجلى عظمة الله وقدرته في خلق الانسان الاول سيدنا ادم من تراب ثم نفخ فيه من روحه وشرفه بذلك على سائر

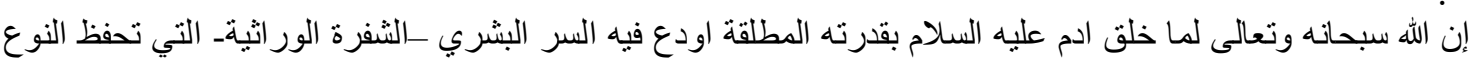

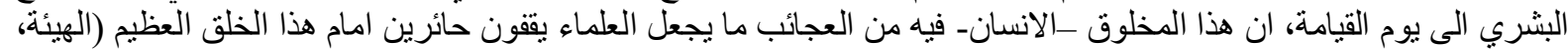

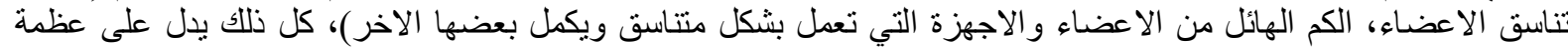
الخالق القدير. و واقتضت طبيعة البحث تقسيمه الى المطالب الاتبة:

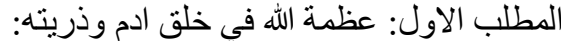

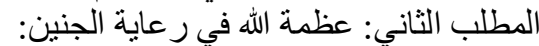

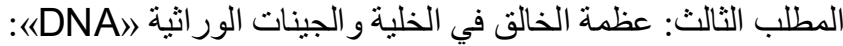
المطلب الر ابع: عجائب خلق الله في جسم الإنسان (خلق الإنسان الإنسان في احسن تقويم): المطلب الخامس: الإعجاز في النفس (الإنسان ذللك الكائن العجيب):

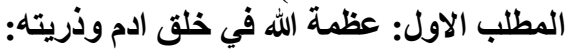

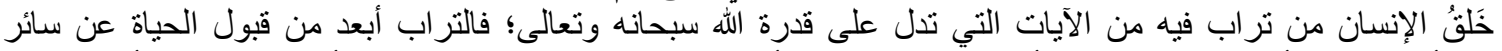

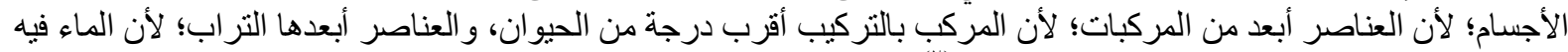

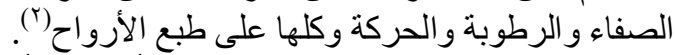

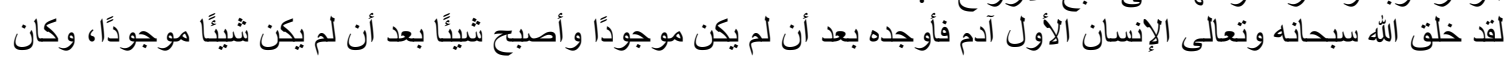

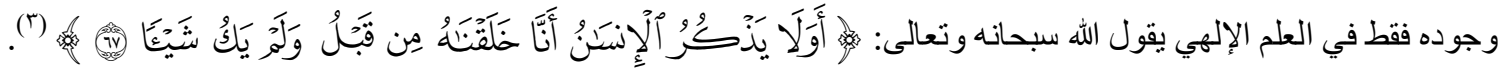

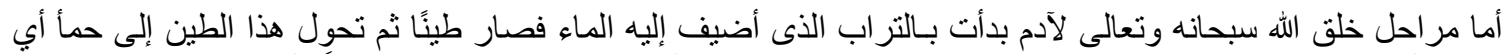

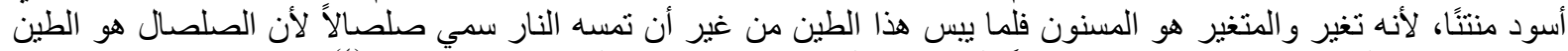

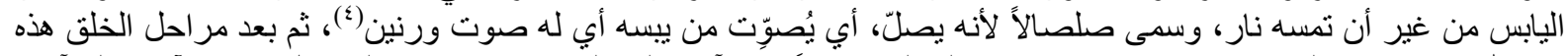

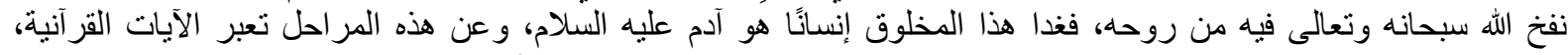

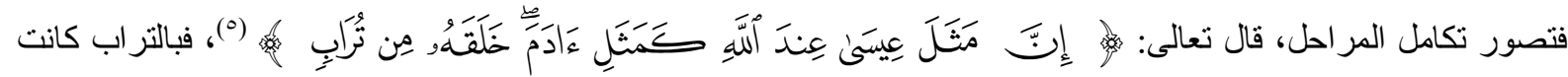

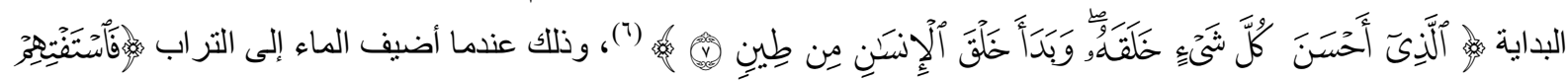

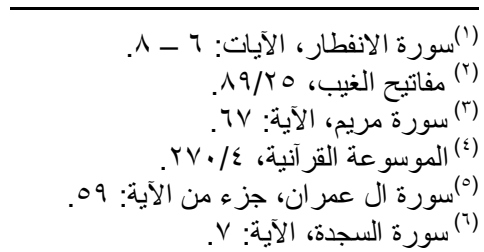




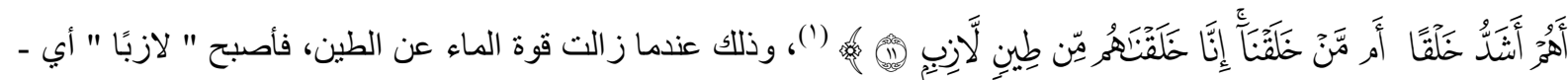

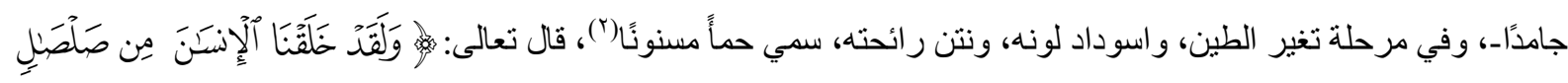

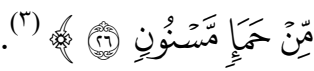

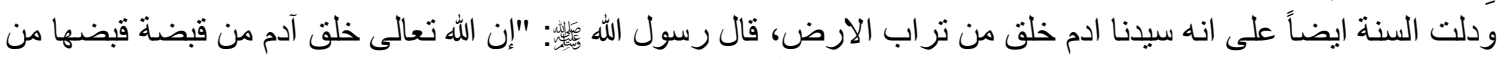

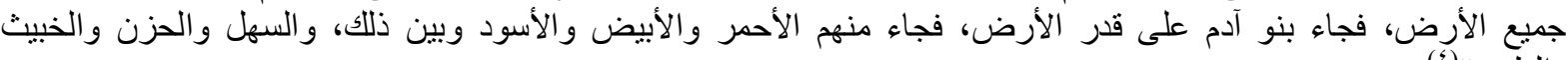

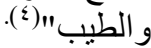

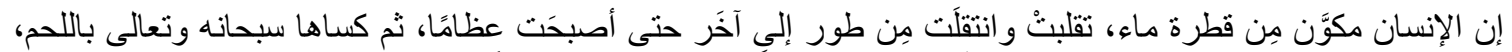

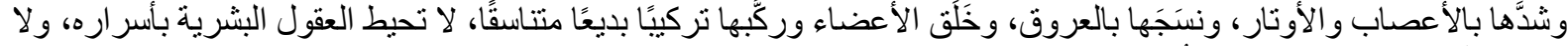
تدرِكِ الأفهام الإنسانية حقيقتَّهَ وكُنْهَها.

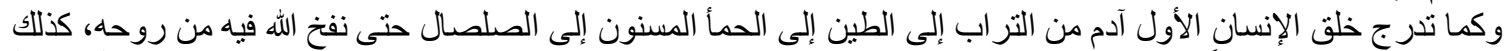

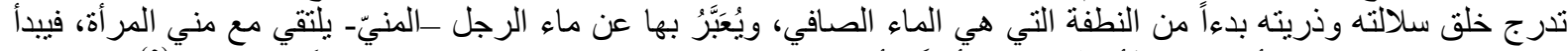

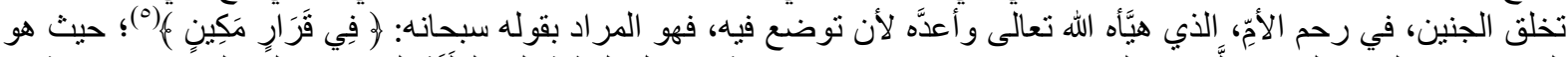

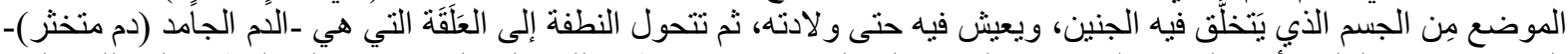

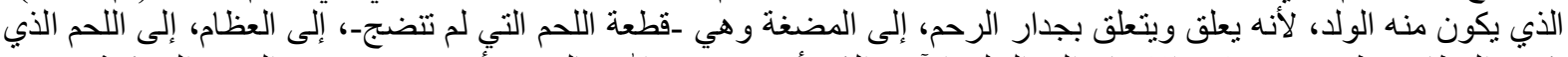

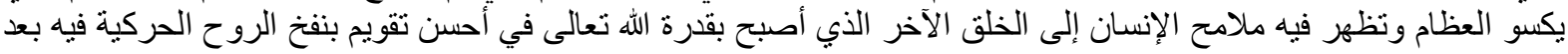

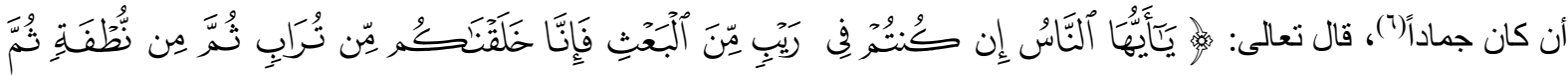

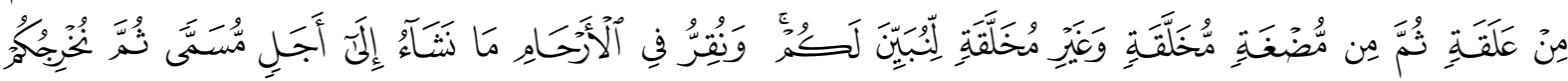

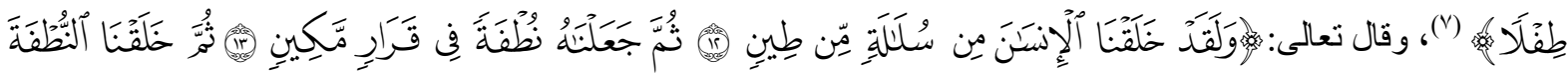

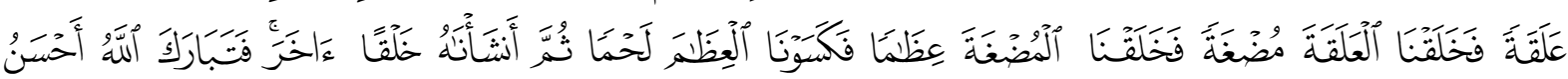

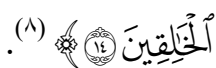

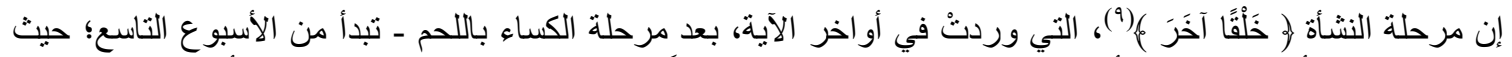

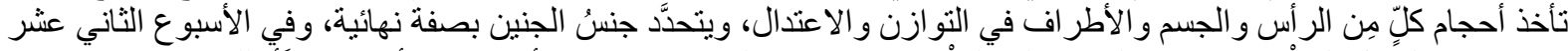

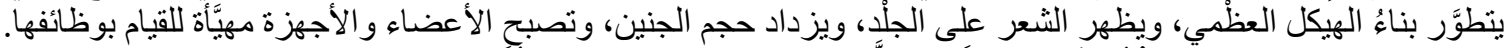

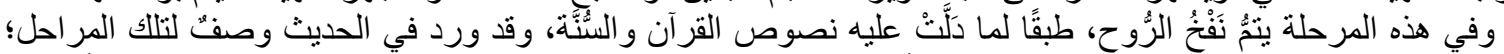

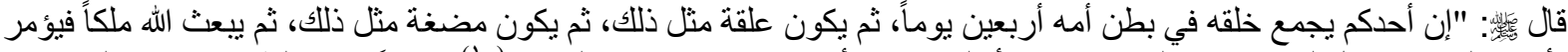

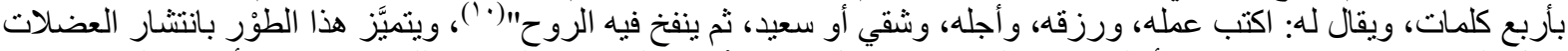

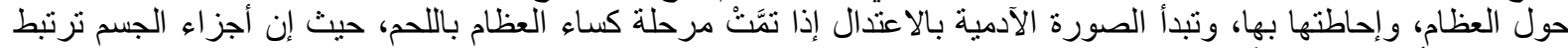

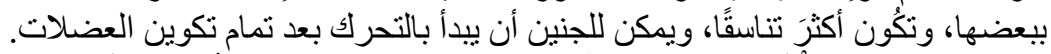

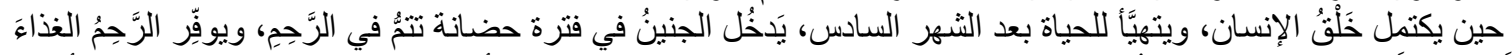

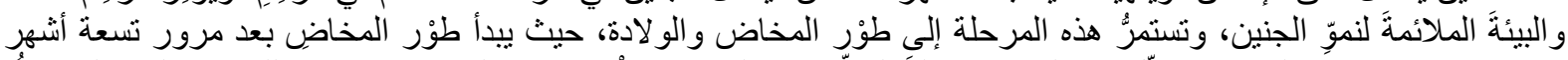

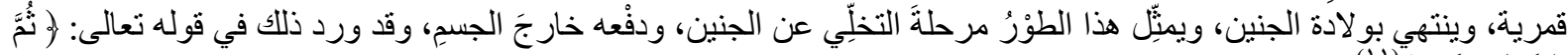

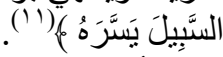

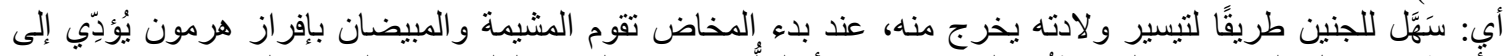

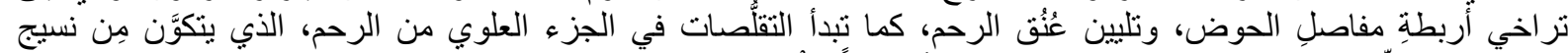

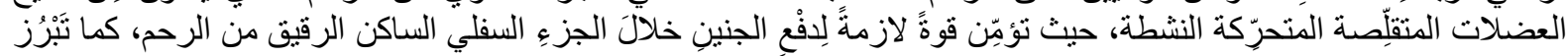

$$
\begin{aligned}
& \text { (') (1) سورة الصافات، الآية: 11) } \\
& \text { (r) }
\end{aligned}
$$

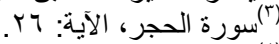

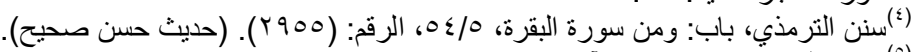

$$
\begin{aligned}
& \text { (0) }
\end{aligned}
$$

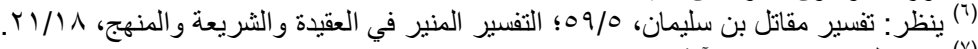

$$
\begin{aligned}
& \text { (ا) } \\
& \text { (^) } \\
& \text { (9) }
\end{aligned}
$$

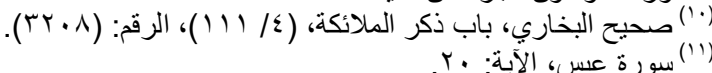




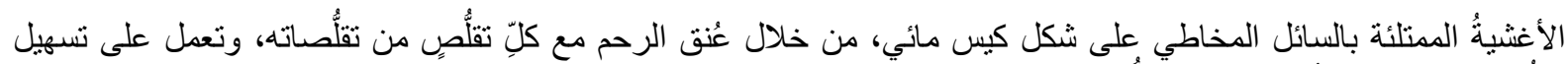

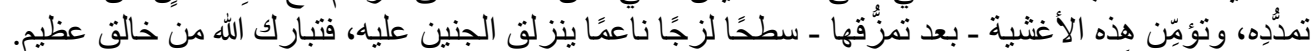

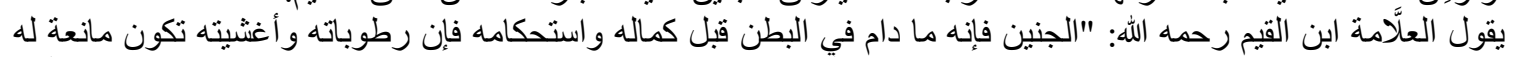

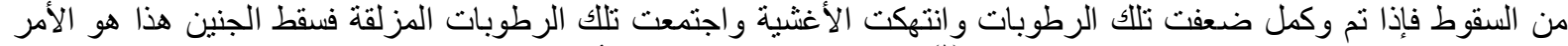

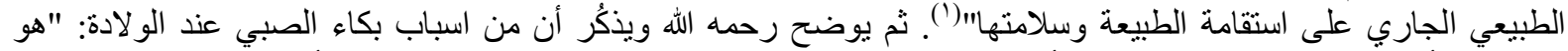

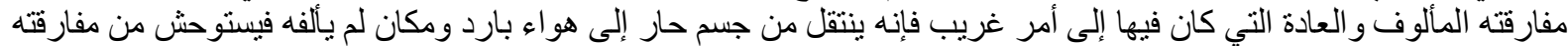

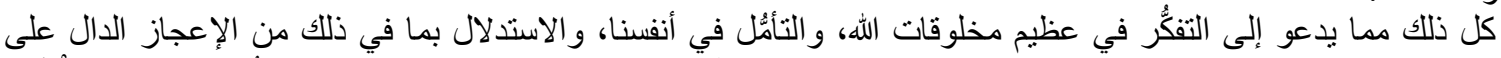

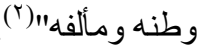

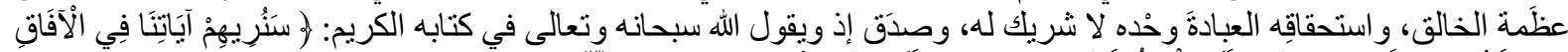

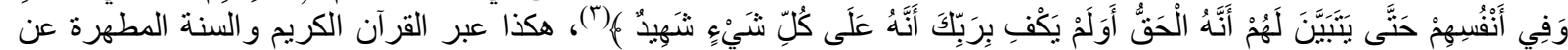
مر أحل خلق الإنسان الأول، وخلق سلالات وذريات هذات الإن الإنسان.

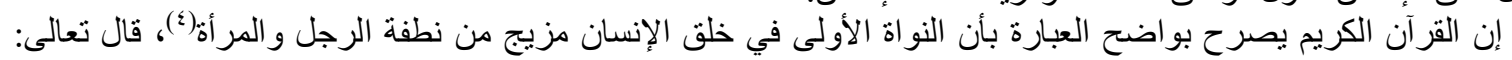

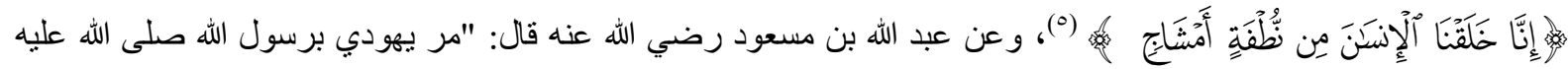

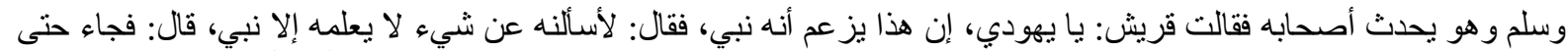

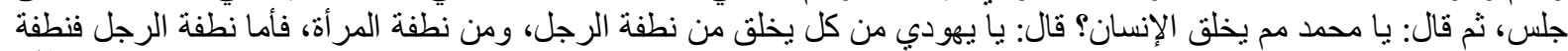

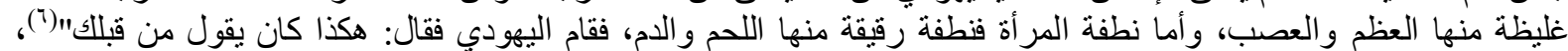

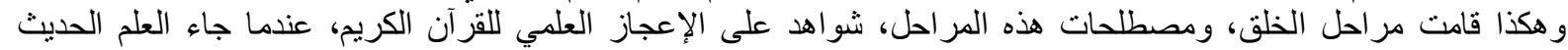

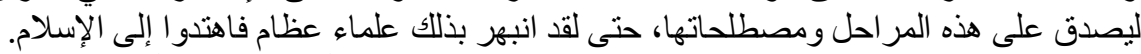

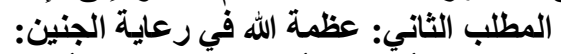

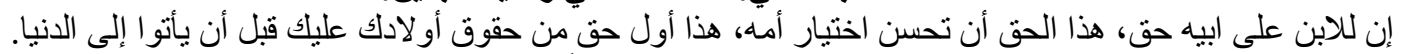

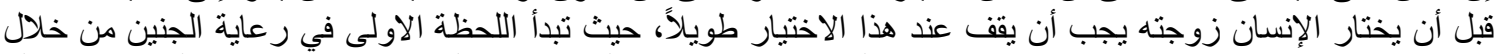

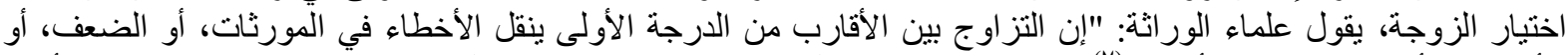

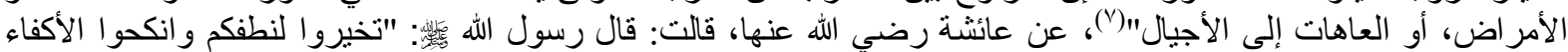

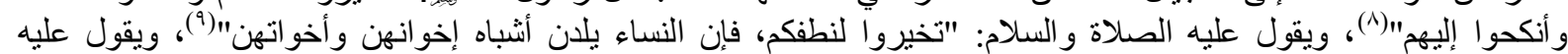

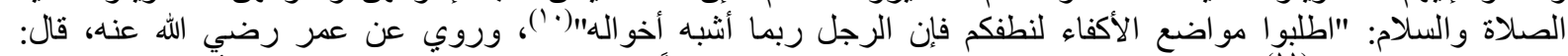

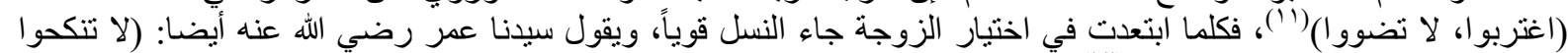

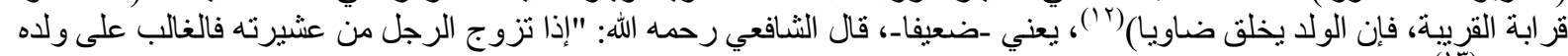

وتحسين النسل يعد من أرقى علوم الور اثثة، أي أن يأتي جيل يتمتع بقدر ات عقلية عالية، وبنية جسمية فائقة، ونفسية متفتحة،

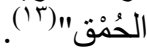

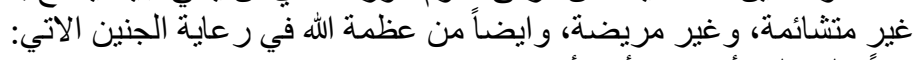

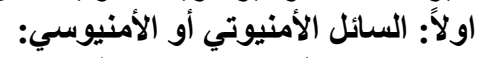

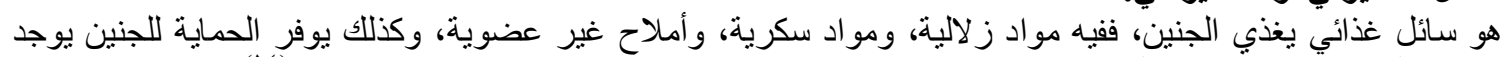

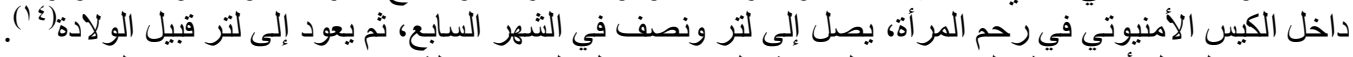

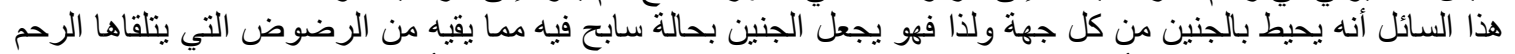

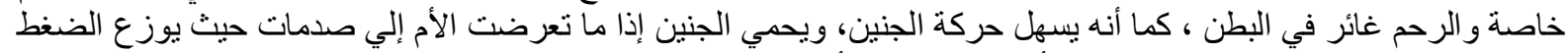

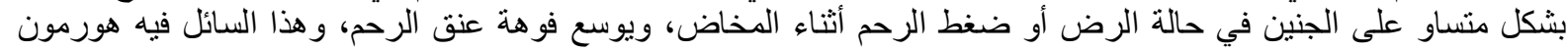

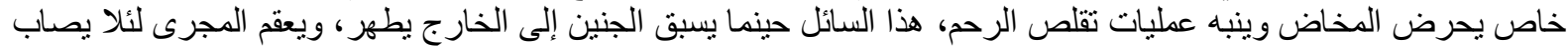

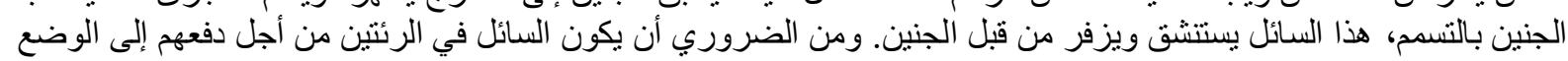

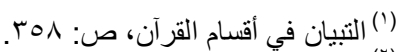

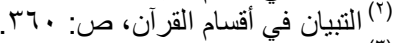

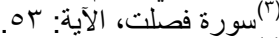

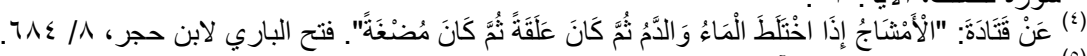

$$
\begin{aligned}
& \text { (0) }
\end{aligned}
$$

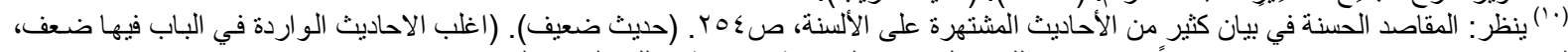

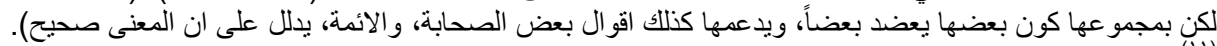
(1) (ז)

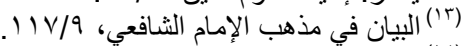

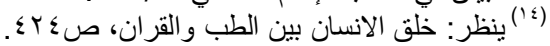


الطبيعي، ابتلاع السائل الأمنيوتي يؤدي أيضا إلى البول ويسهم في تشكيل العقي، ويحمي الطفل من التصاق أعضائه الظاهرة

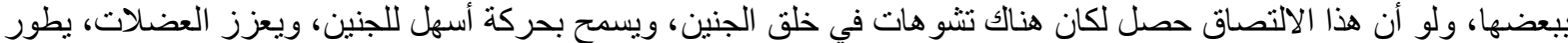

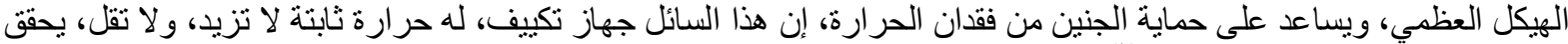

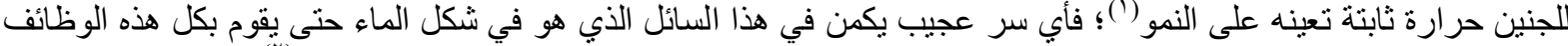

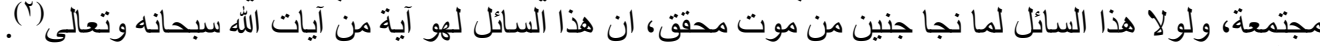

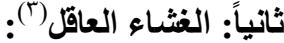

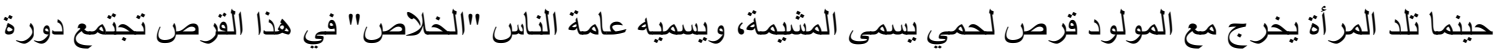

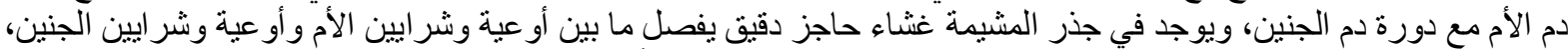

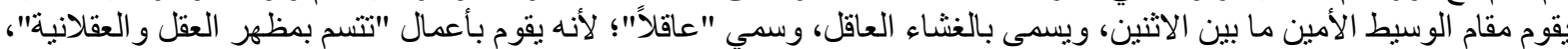

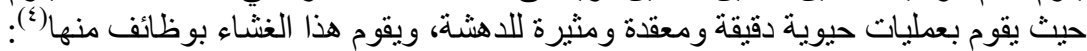

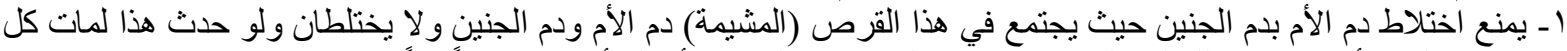

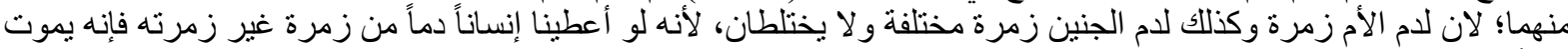

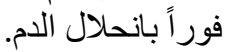

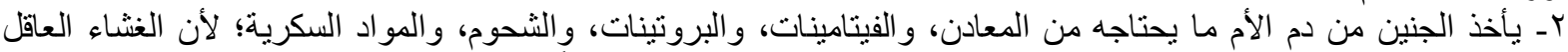

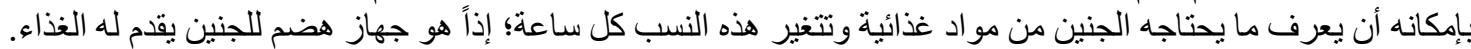

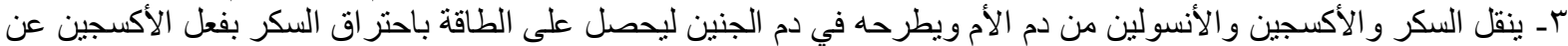

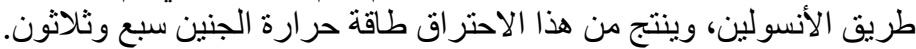

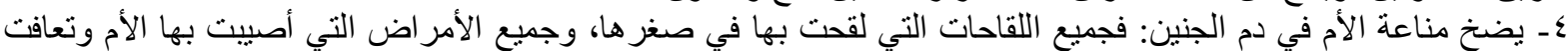

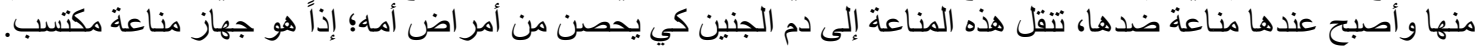

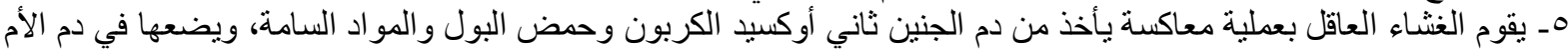

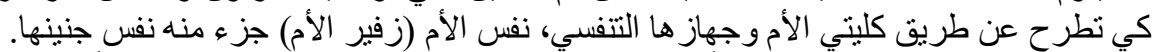

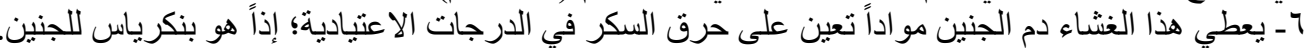

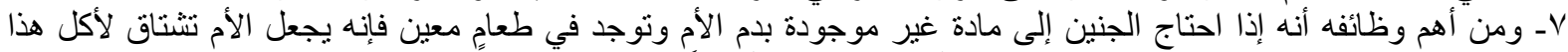

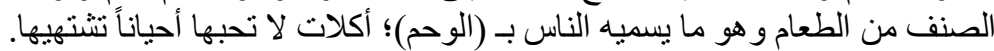

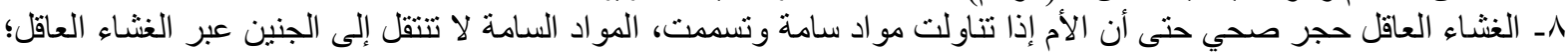

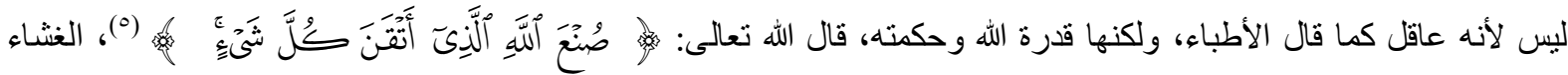

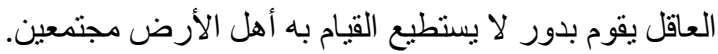

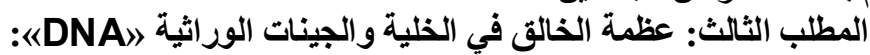

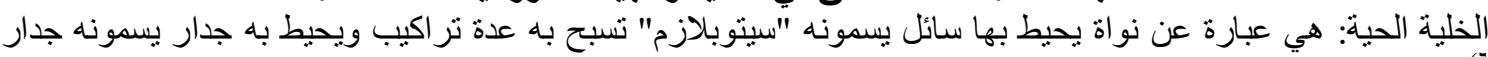
الخلية(†).

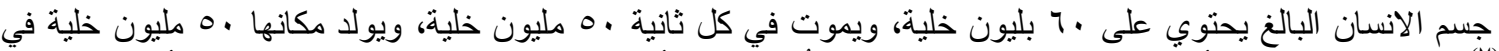

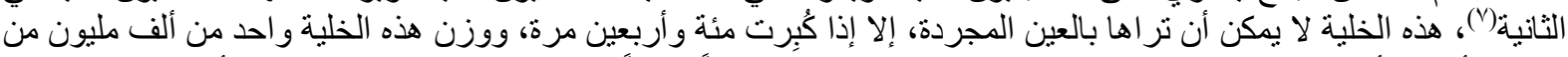

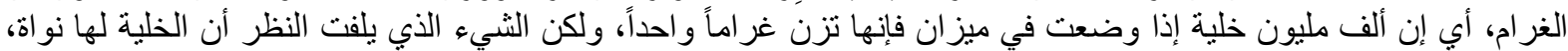

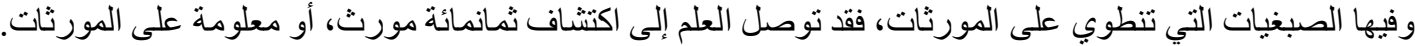

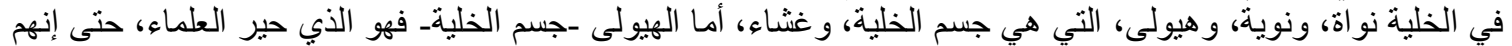

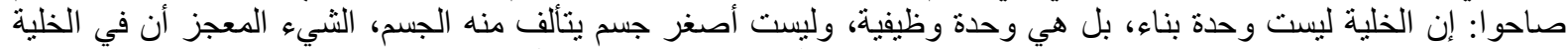

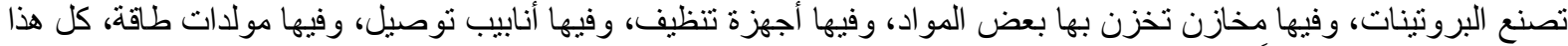

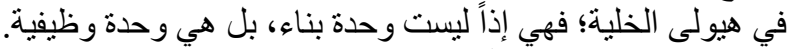

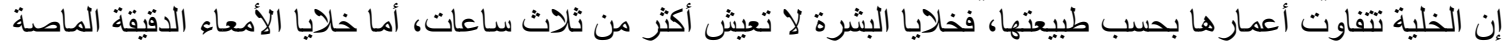

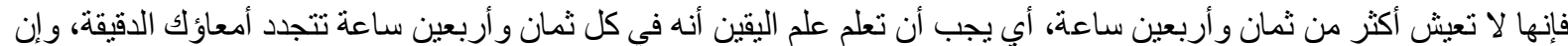

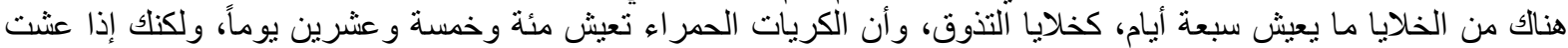

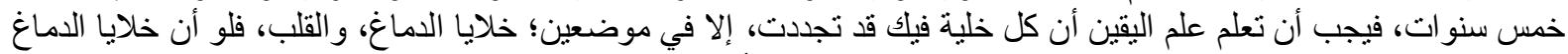
تجددت لنسي الإنسان معلوماته؛ لذللك شاءت حكمة الله عز وجل أن تبقى خلايا الدماغ في الجنين حتى الموت، وكلئ وللك خلايا

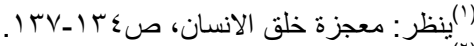

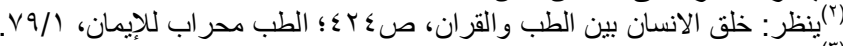
(")

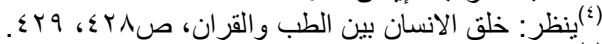

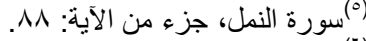

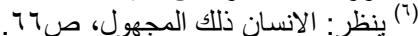

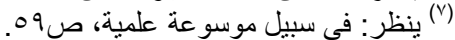


القلب(')، إن خلايا الجسم، الخلايا العظية، و العضلات، و الثعر، وأية خلية في الجسم تتبدل من خمس إلى سبع سنو ات، فأنت بعد

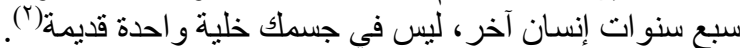

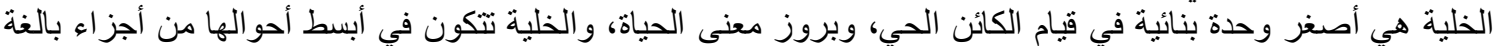

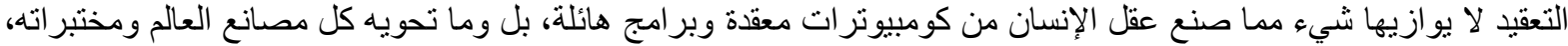

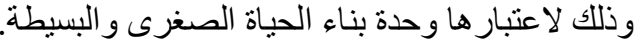

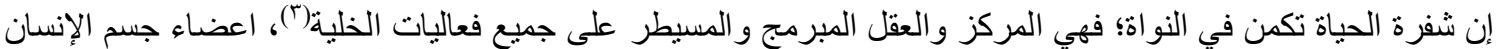

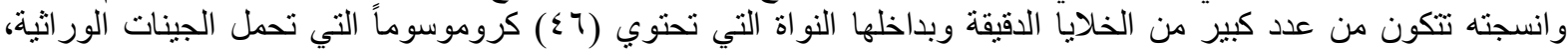

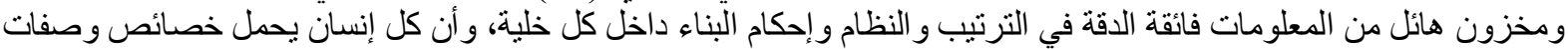

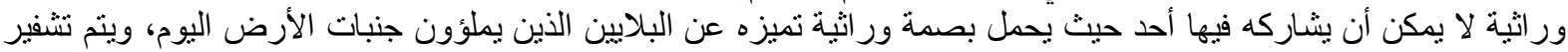

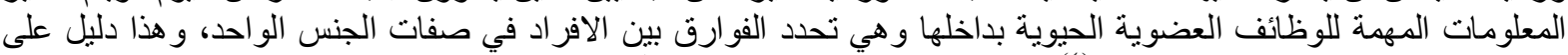

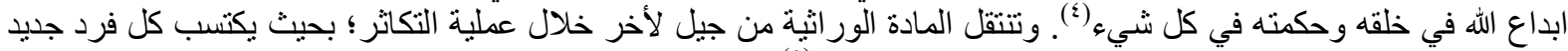

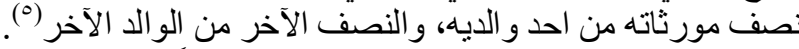

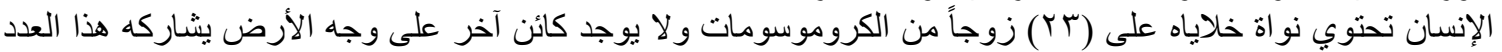

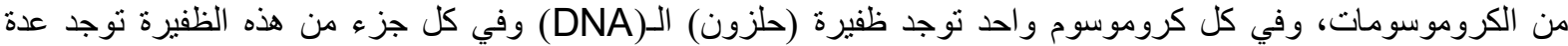

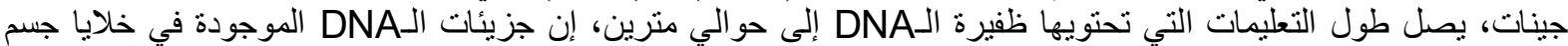

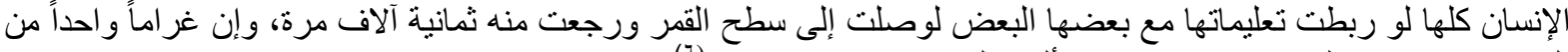

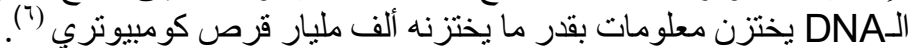

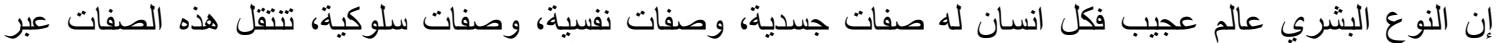

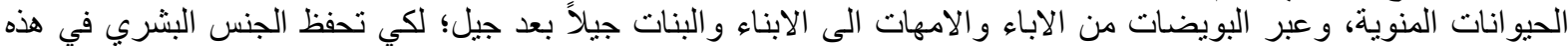

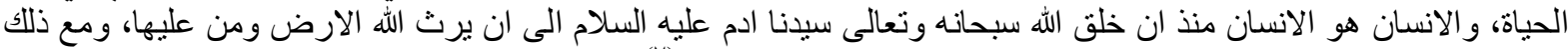

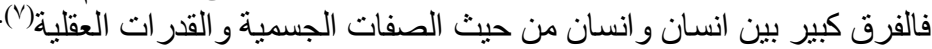

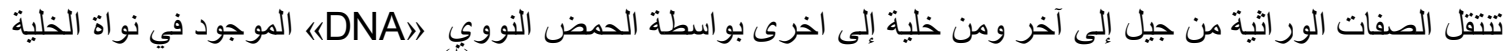

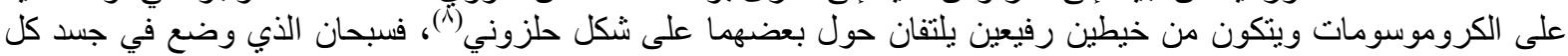

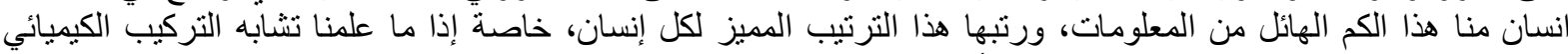

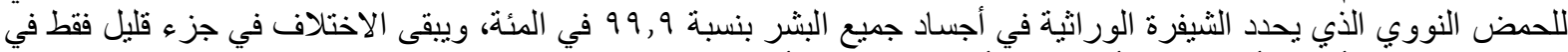

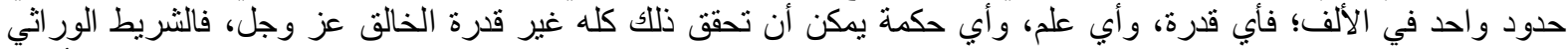

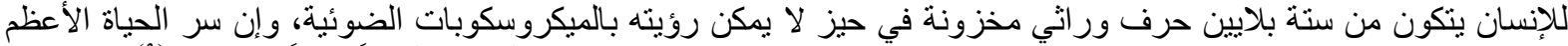

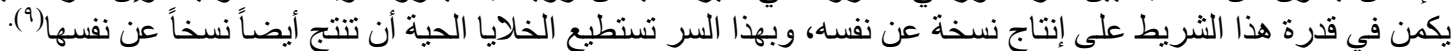

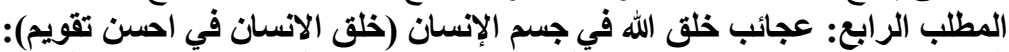

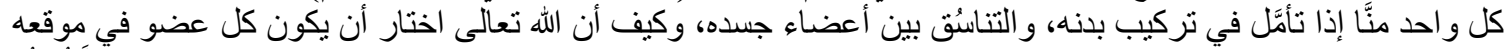

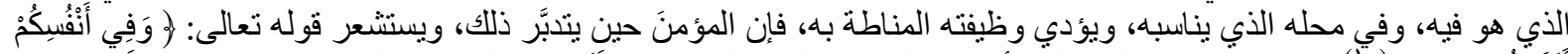

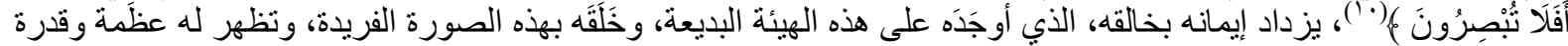

فانظر إلى بعض ما خصك وفضلك به على البهائم، إذ خلقك على هيئة تنتصب قائماً، وتستوي جالساً، وتستقبل الأشياء الخالق.

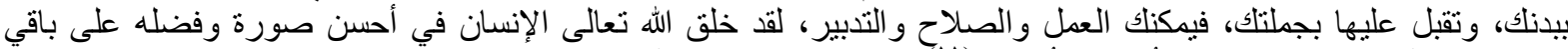

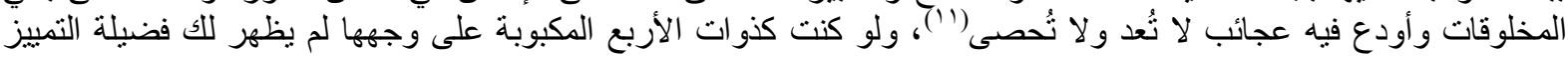

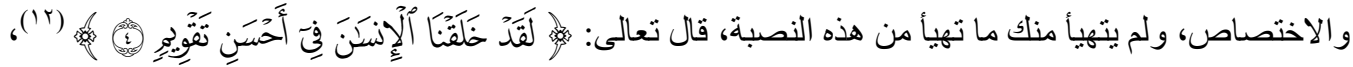

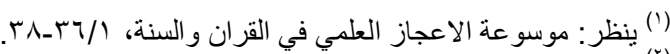

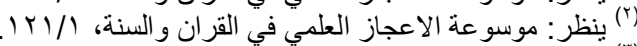

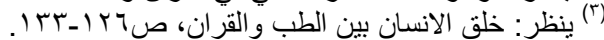

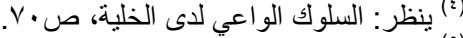

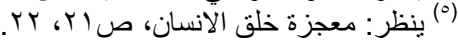

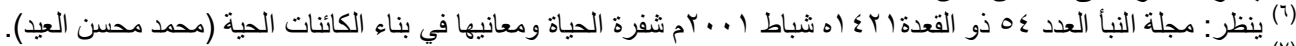

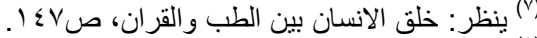

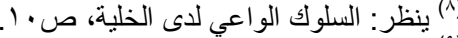

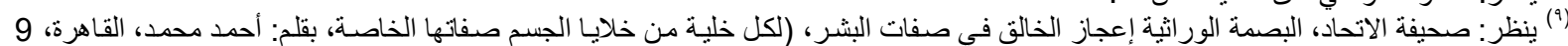




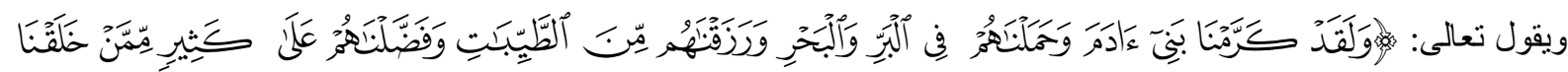

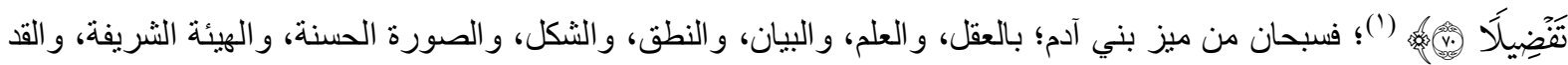

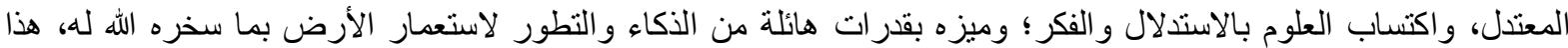

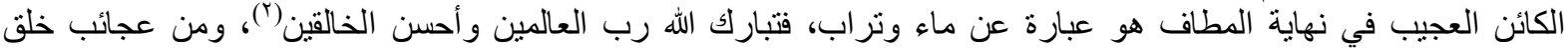
الإنسان ان جسمه يتألف من عدد ضخم من الأجهزة منها: العناء

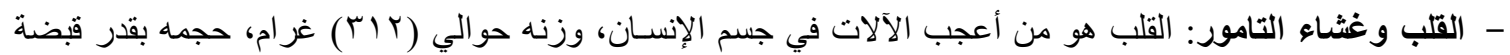

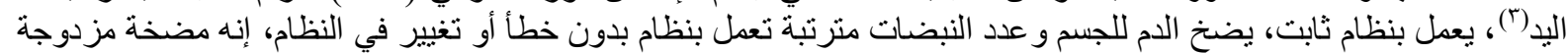

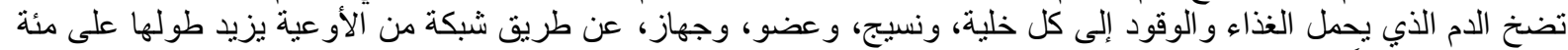

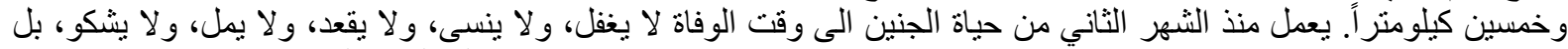

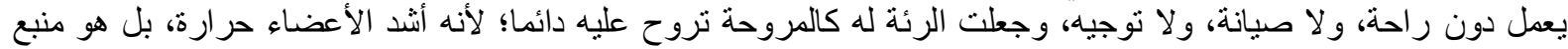
الحرارة.

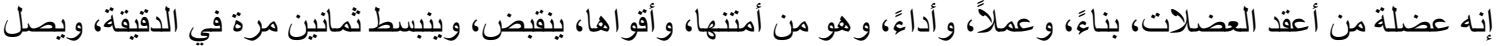

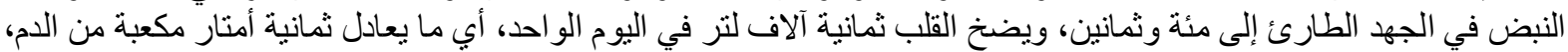

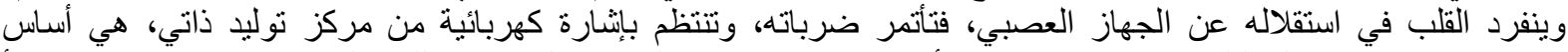

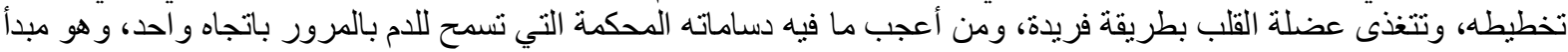

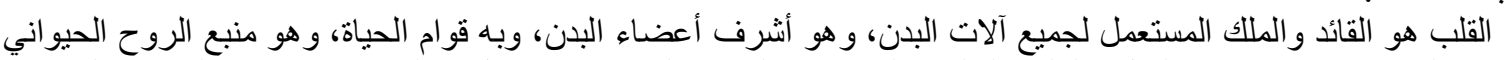

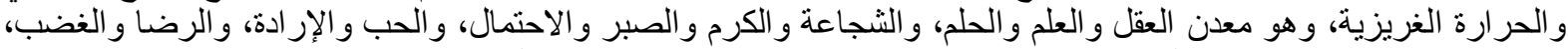

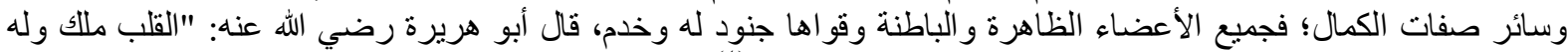

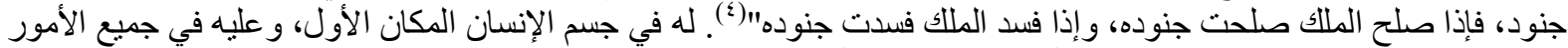

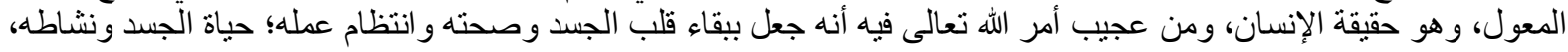

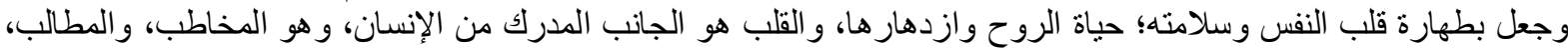

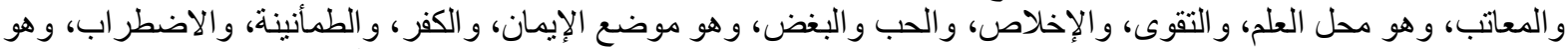

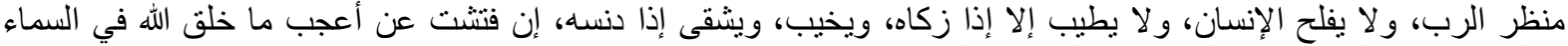

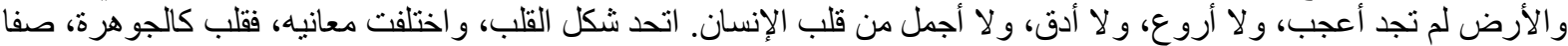

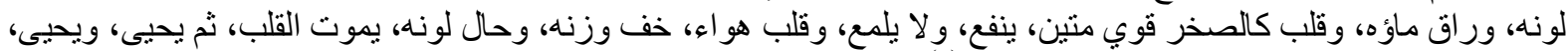

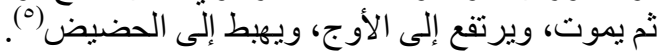

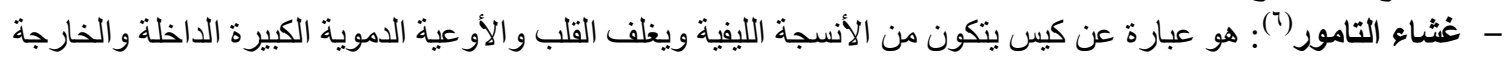

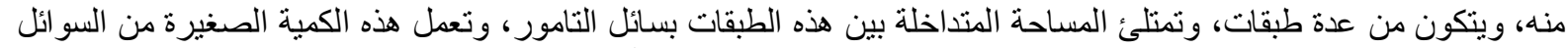

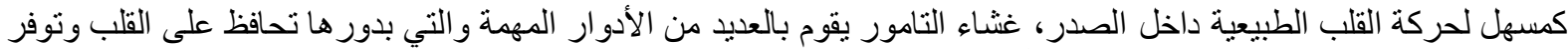

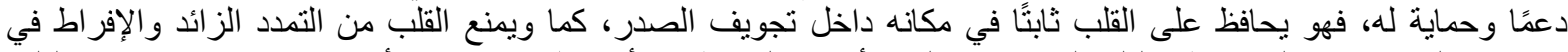

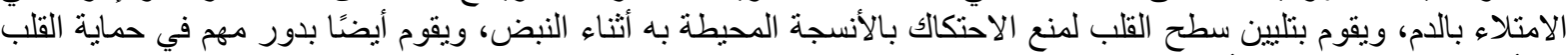

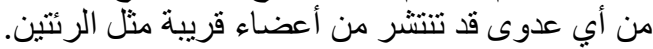

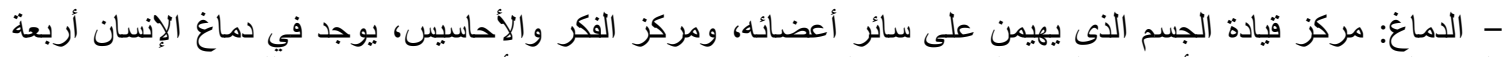

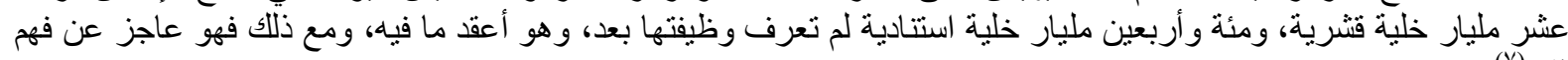

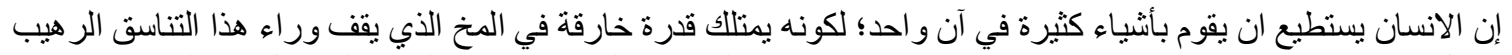

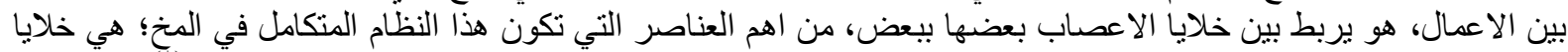

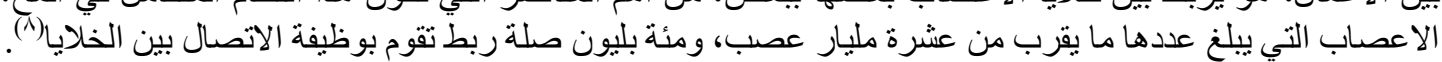

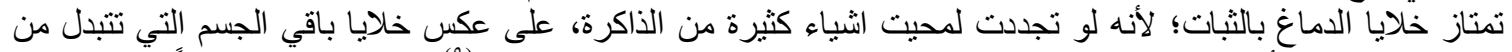

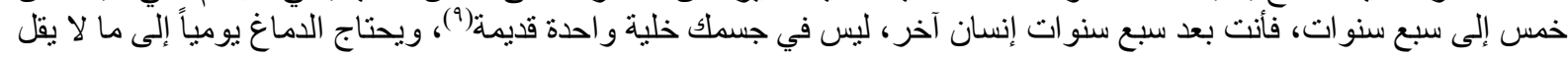

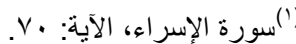

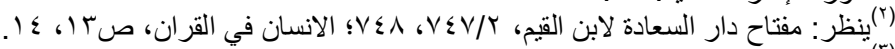

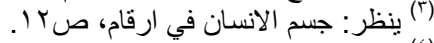

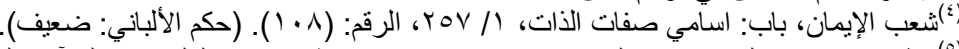

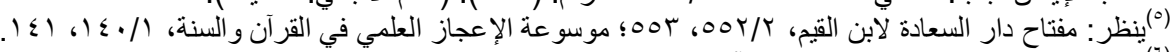

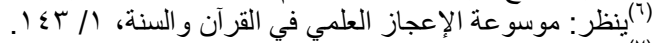

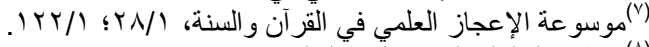

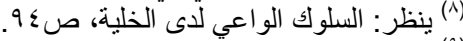

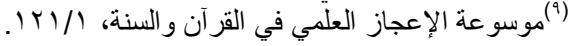




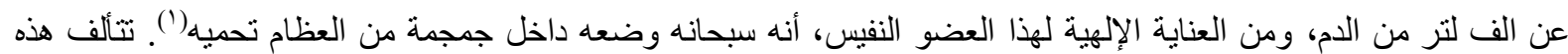

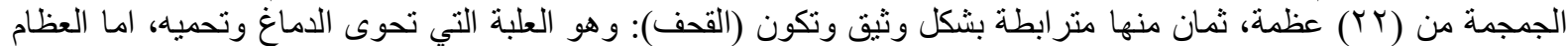

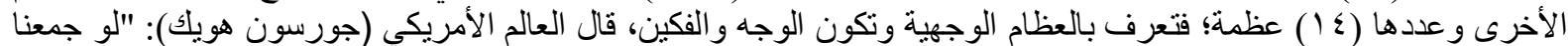

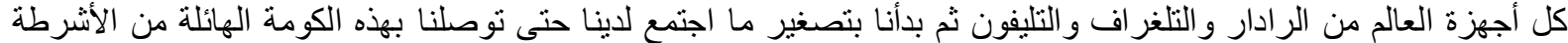

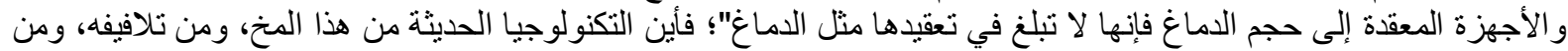

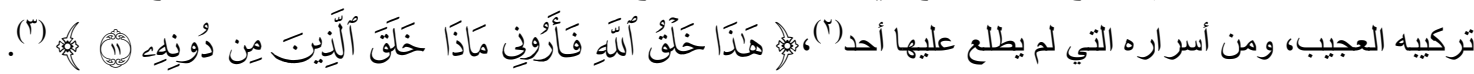

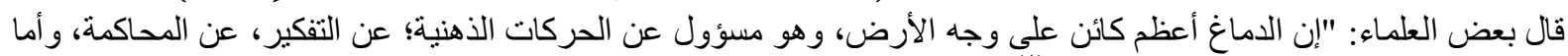

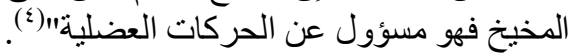

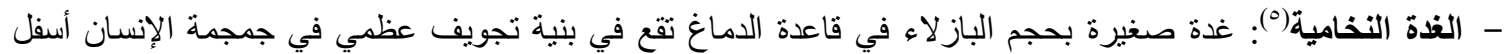

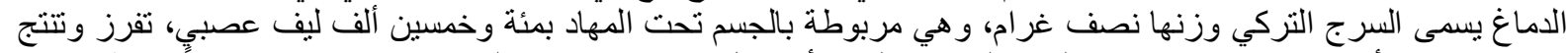

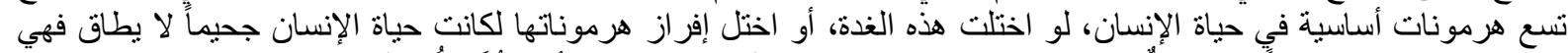

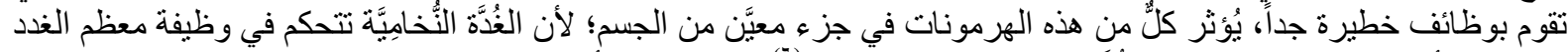

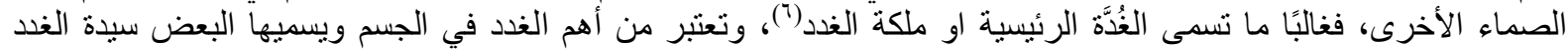
الصماء.

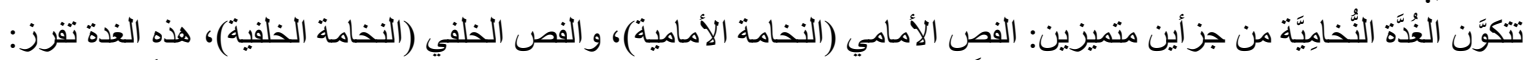

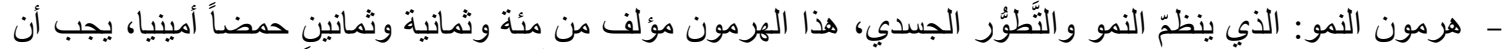

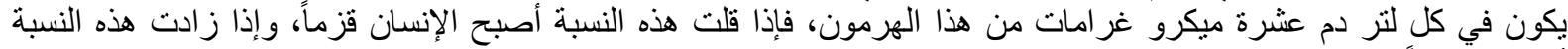

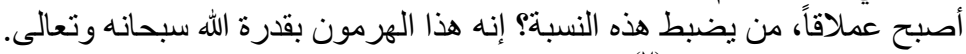

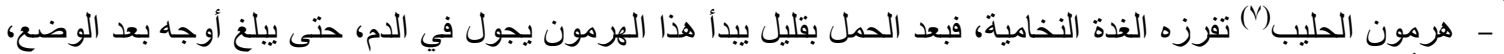

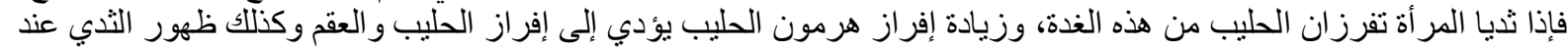

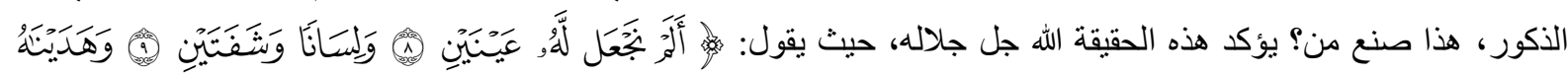

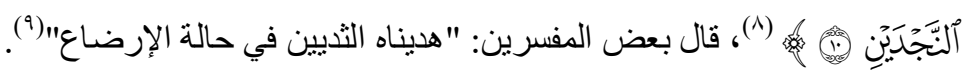

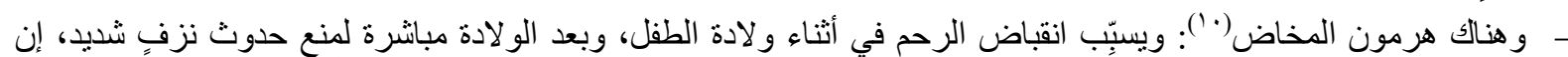

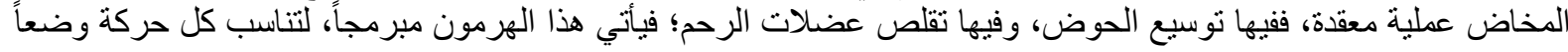

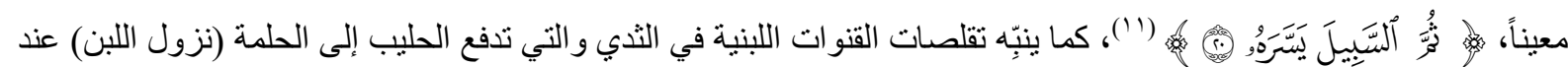
المرضعات.

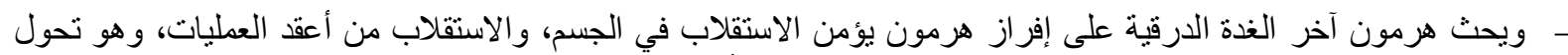

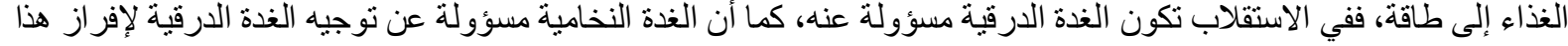

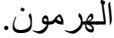

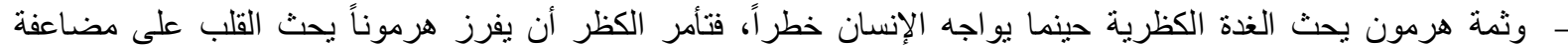

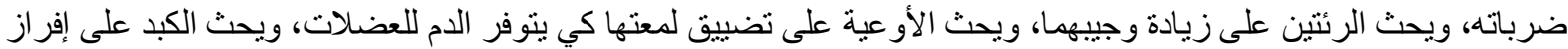

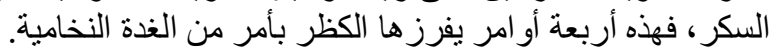

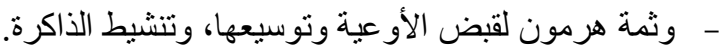
- إن هرمون النمو الجنسي مسؤولة عنه الغدة النخامية في الدماغ، و إن صفات كل من الذئكر و الأنثى تكون بفعل هرمون تفرزه

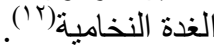

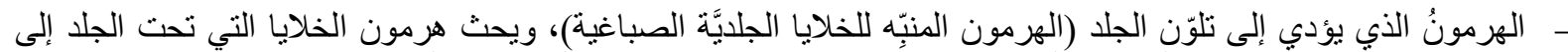
إفر از المادة الملونة للإنسان، من أبيض، وأسمر، وحنطي، وملون، وتلك التي تتبط أحاسيس الألم، وتساعد على التحكم في الجهاز

المناعي.

$$
\begin{aligned}
& \text { (') ينظر: الانسان ذلك المجهول، صعاب. } \\
& \text { (r) }
\end{aligned}
$$

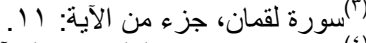

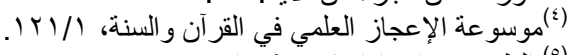

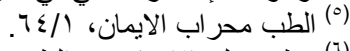

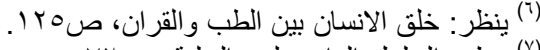

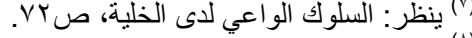

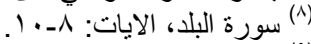

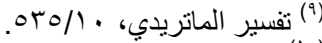

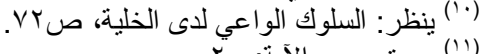

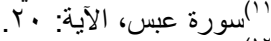

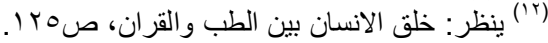




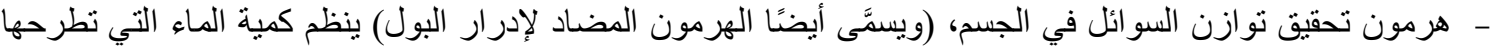

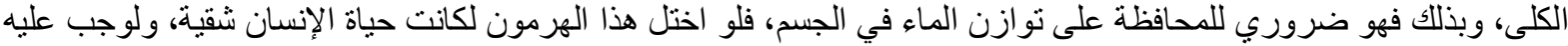

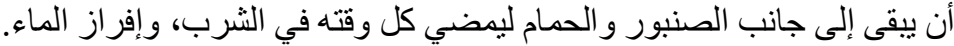

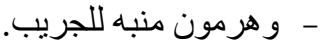

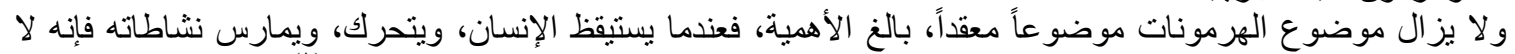

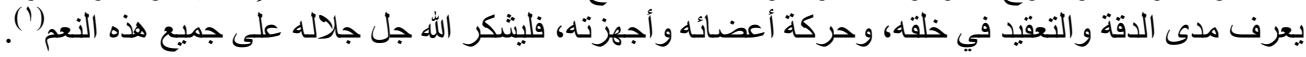

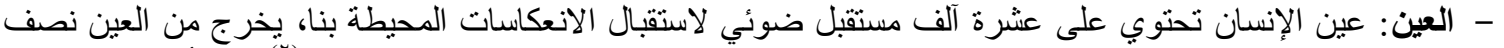

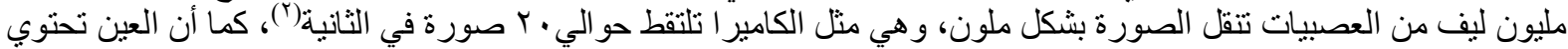

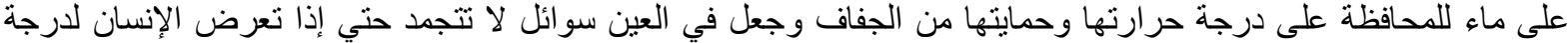

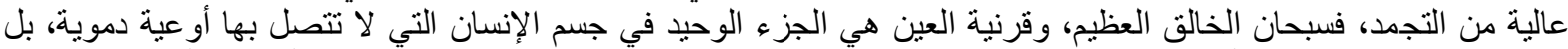

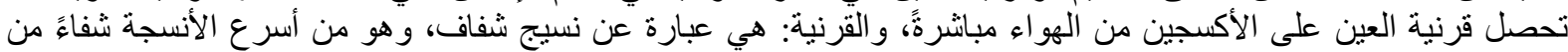

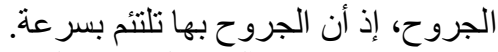

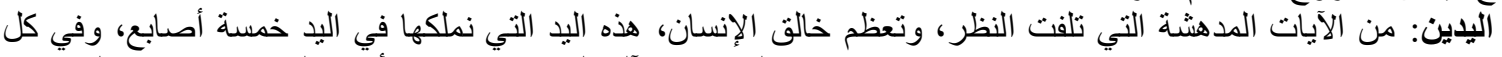

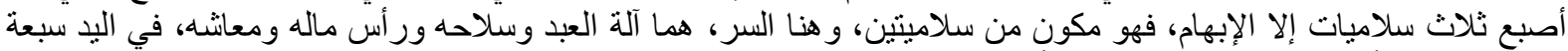

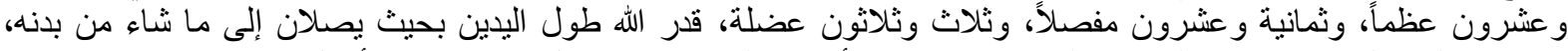

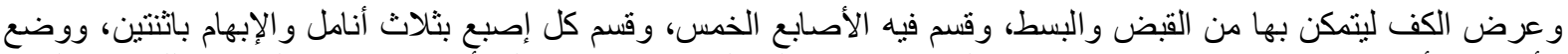

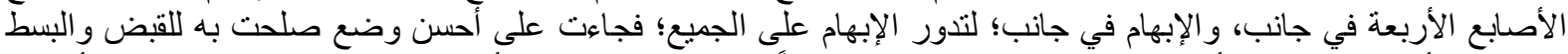

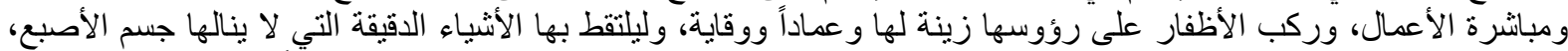

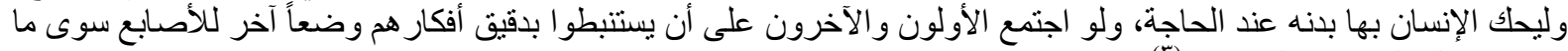

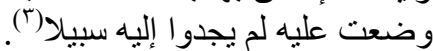

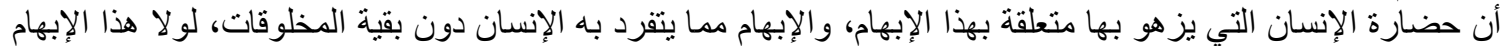

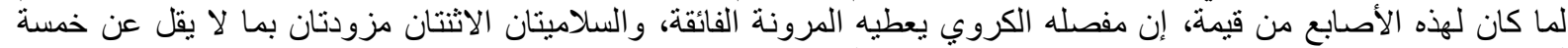

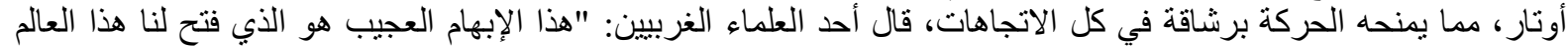

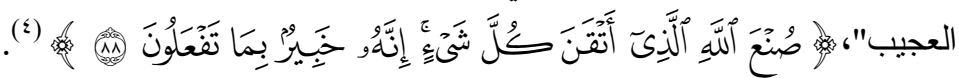

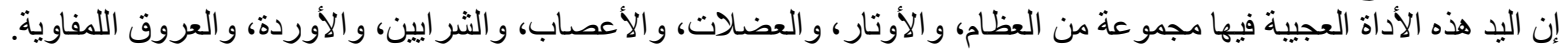

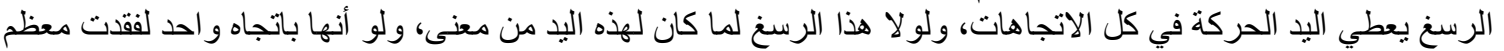

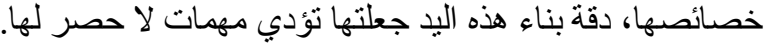
هذه اليد آية من آيات الله عز وجل، هذه الحضارة، هذه الصناعات، هذه الآلات، لا معنى لها دون يد، والله جل جلاله كرم

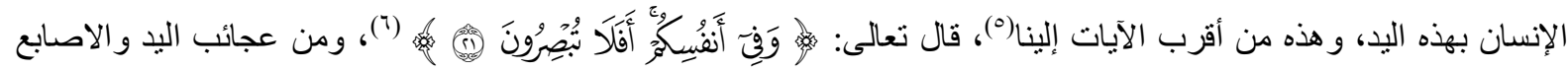

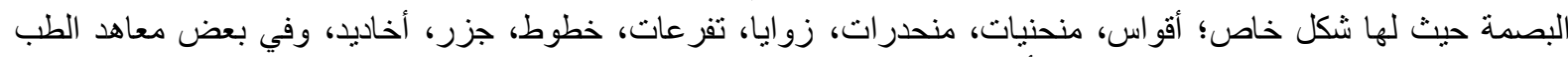

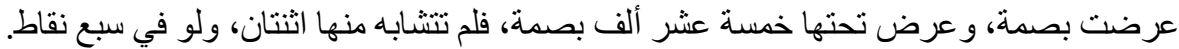

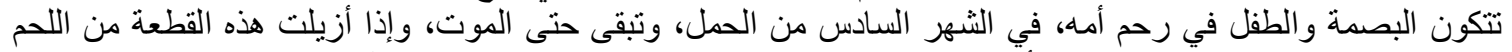
إزالة كلية نبت لحم جليد عليه البصمة التي أزيلت، إن البصمة سجل، وهوية، ونوقيع من صنع الله عز وجل منحه للإنسان، لا لا

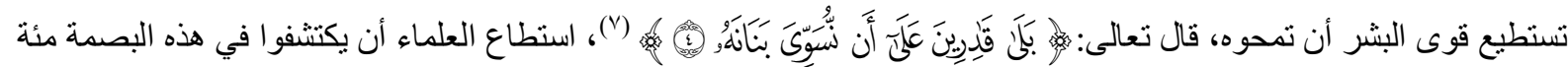

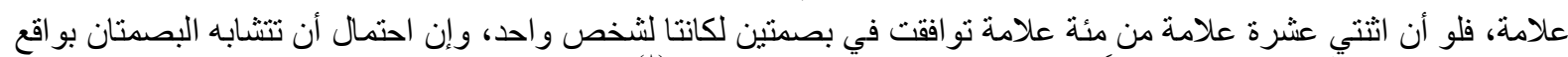

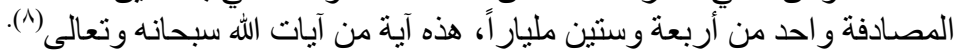

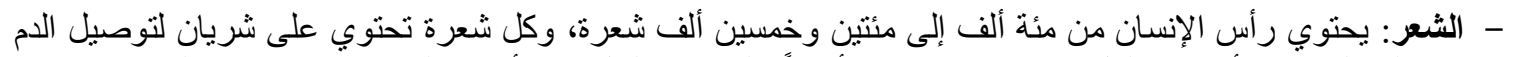

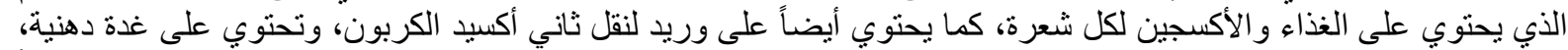

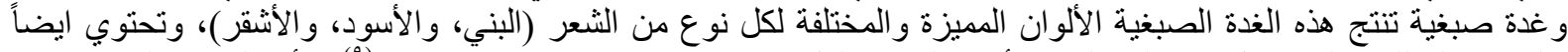

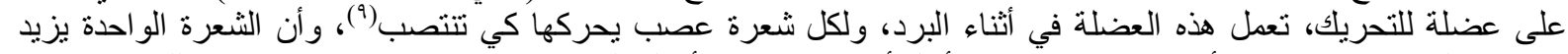

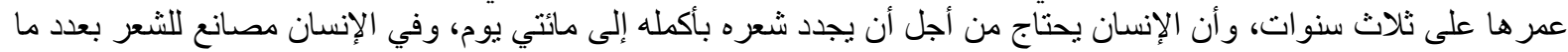

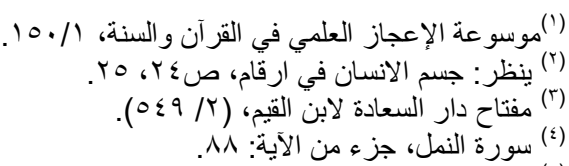

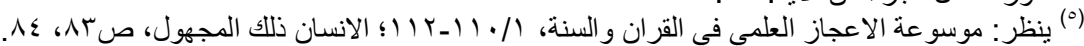

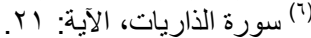

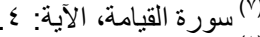

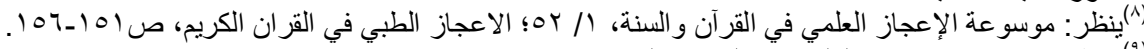

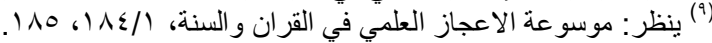




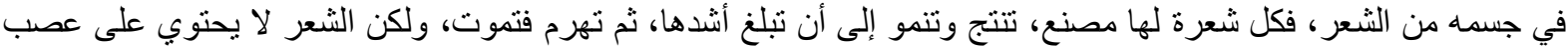

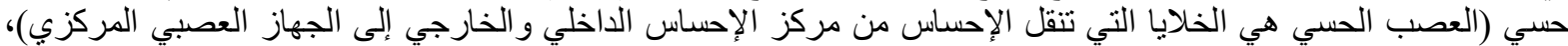

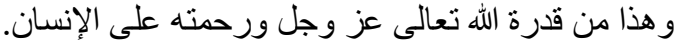

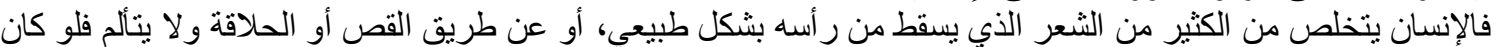

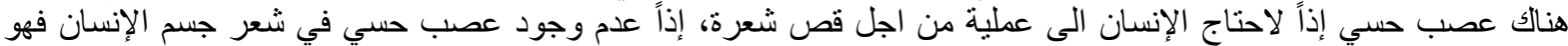

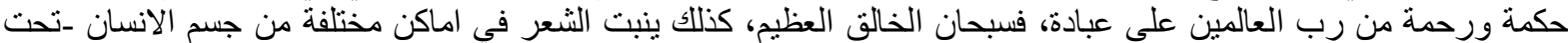

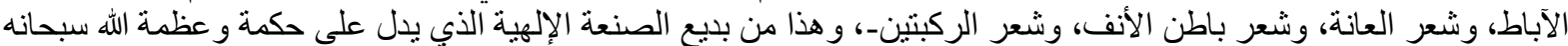

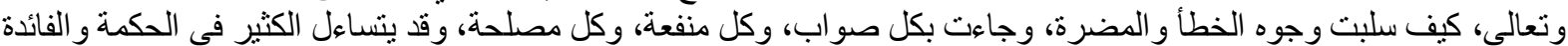

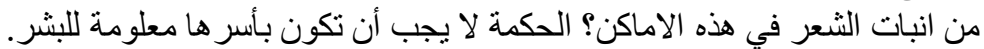

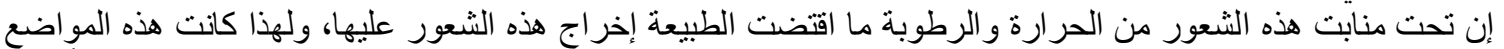

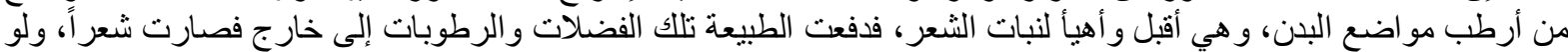

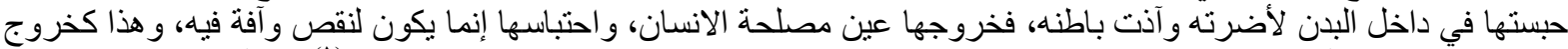

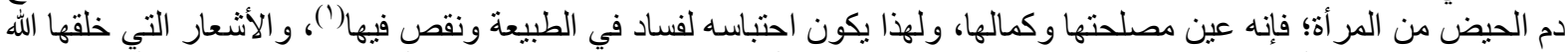

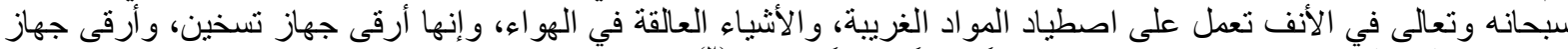

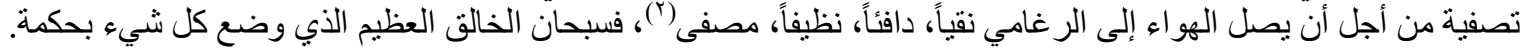

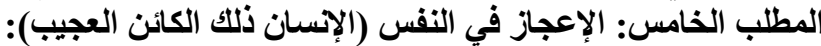

مسألة النفس من المسائل المعقدة، فاستأثرت بقدر كبير من جهود الإنسانية للتعرف على ماهيتها ولإنيان وطبيعتها و علاقتها بالسلوك الإنساني، فهي المكون الأول للشخصية الإنسانية. "إن النفس الإنسانية هي الكمال الأول لجسم طبيعي آلي من جهة ما يفعل الأفاعيل بالاختيار العقلي، والاستنباط بالر أي، ومن

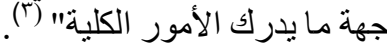
"إن الله الذي خلق هذه النفس وسو اها بما و هبها من المشاعر و العقل، قد جعلها بإلهام الفطرة والغريزة مستعدة للفجور الذي وني

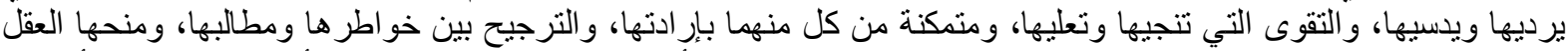

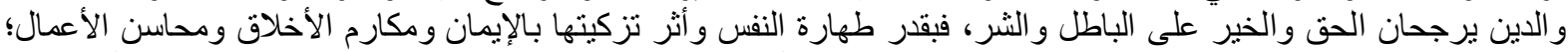

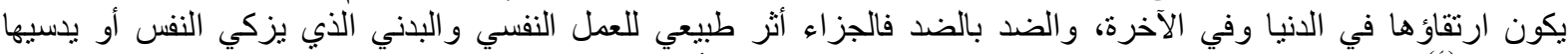

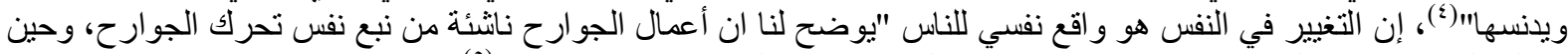

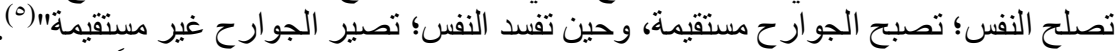

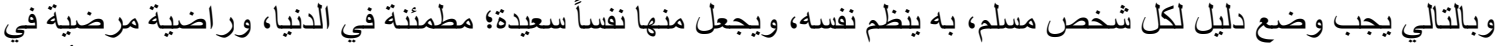

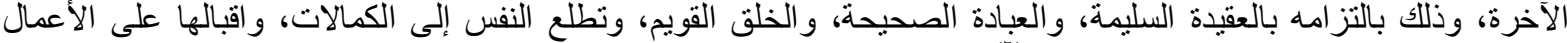

الصالحة تكسب الر احة في الدنباو وعيشة هنيئة (ج).

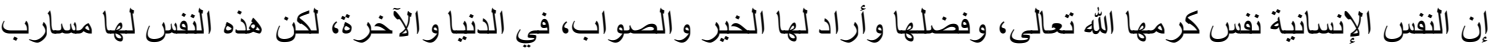

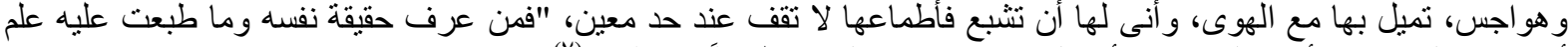

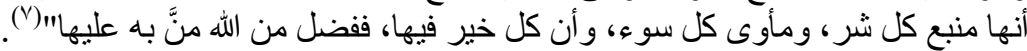

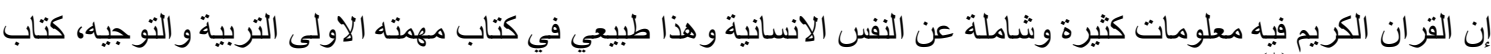

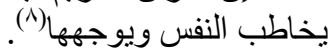

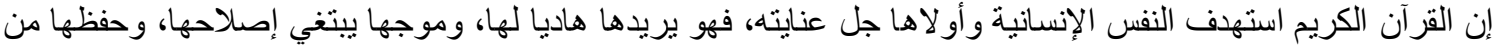

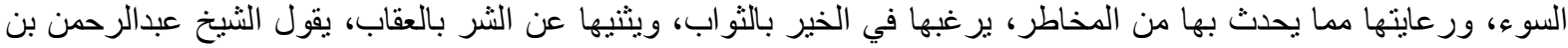

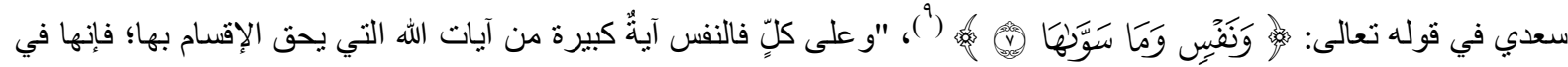

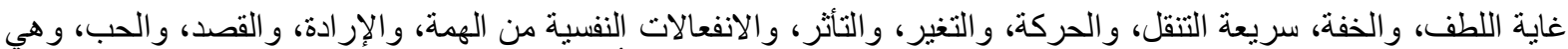

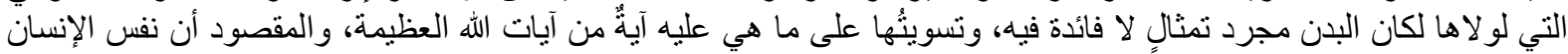

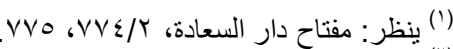

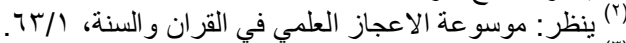

(")

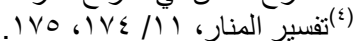

(0)

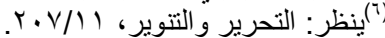

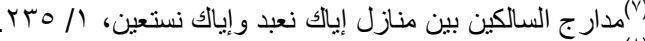

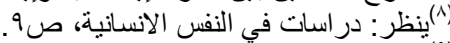

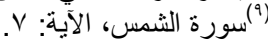


من أعظم الأدلة على وجود الله وحده، ومن ثم تفرده بالعبادة"(')، ويقول ابن تيمية: "الإنسان عبارة عن البدن و الروح معا، بل هو

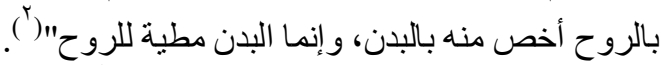

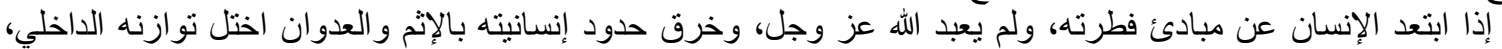

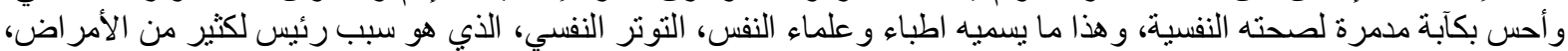

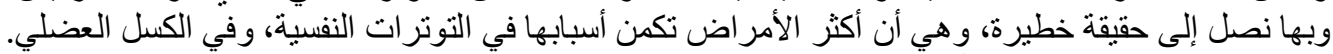

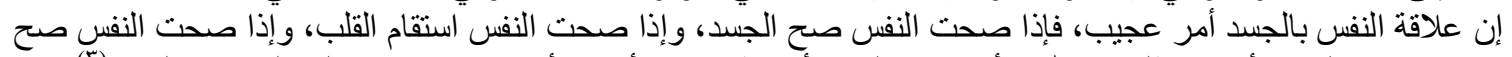

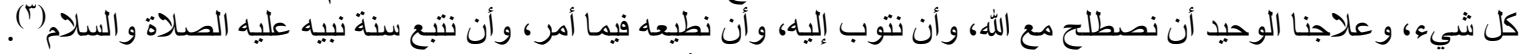
الخاتمة الخان

خلق الله الإنسان وجعله خليفته في الأرض، وكرمه عن سائر المخلوقات بالعقل، و اهر الملائكة بالسجود لـه، الإنه

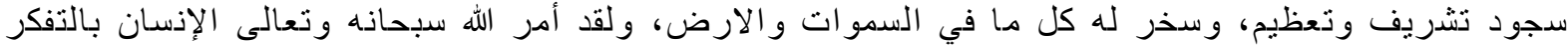

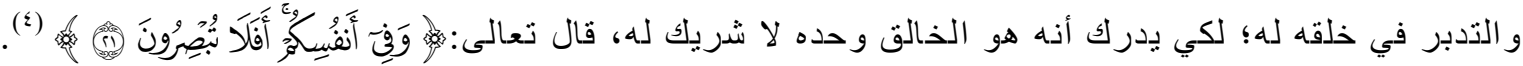

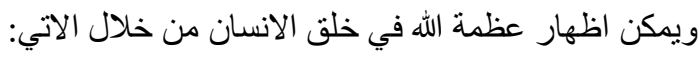

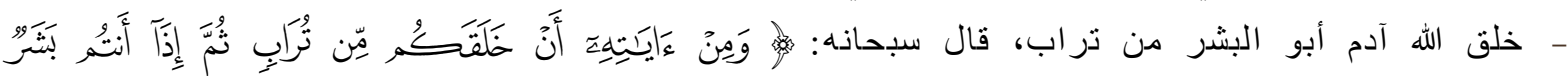

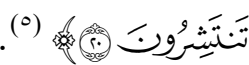

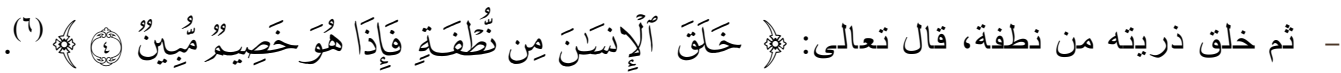

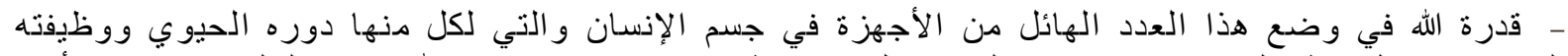

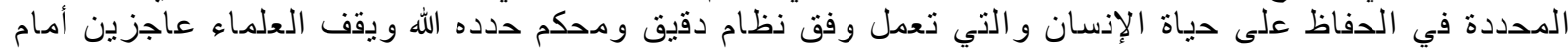

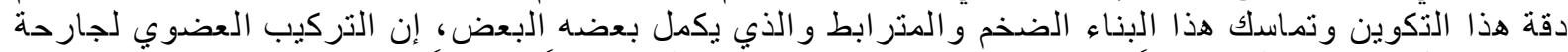

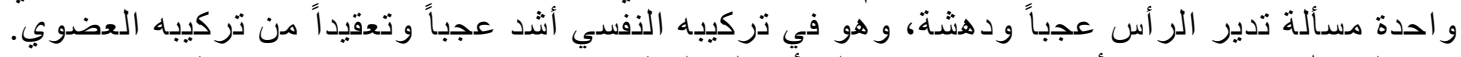

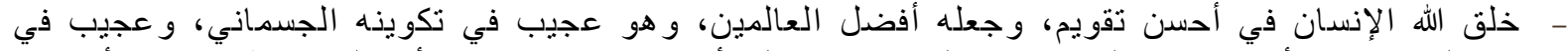

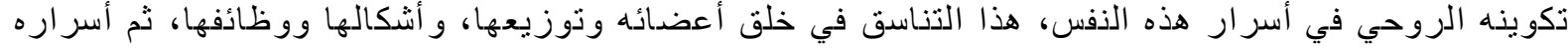

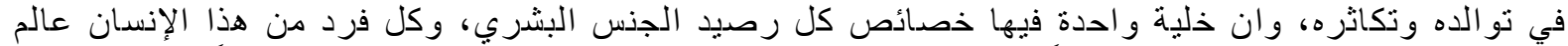

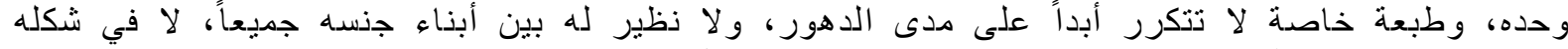

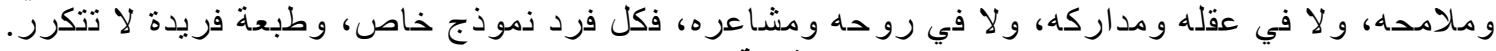

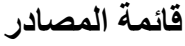

$$
\text { - - - - القران الكريم }
$$

- - صحيفة الاتحاد، البصمة الور اثية إعجاز الخالق في صفات البشر، (لكل خلية من خلايا الجسم صفاتها الخاصة، بقلم: أحمد

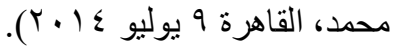

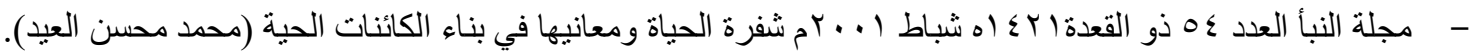

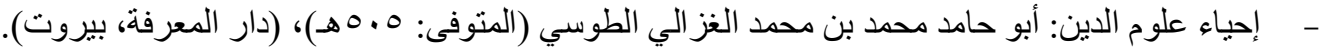

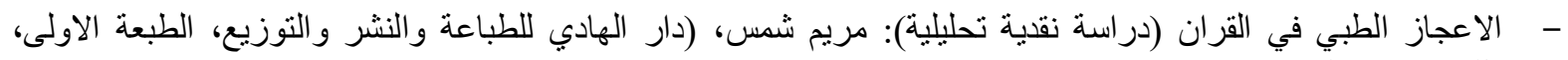

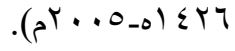

- - الانسان ذللك المجهول: الكسيس كاريل، ترجمة: عادل شفيق، (الدار القومية للطباعة و النشر).

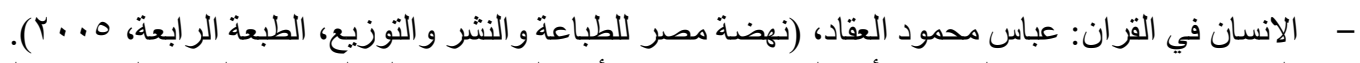

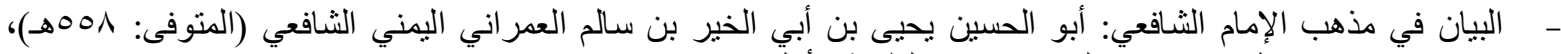

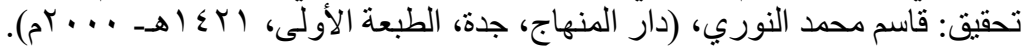

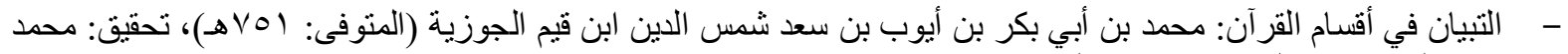

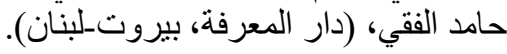

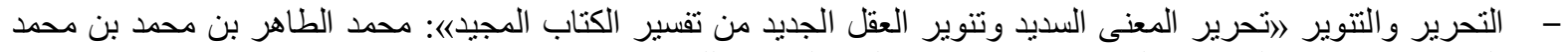

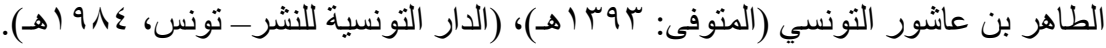

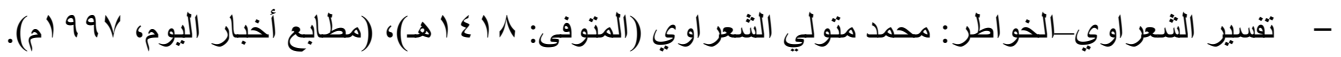

$$
\begin{aligned}
& \text { (1) }
\end{aligned}
$$

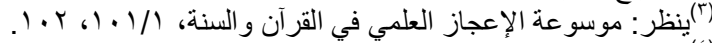

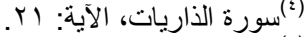

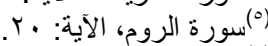

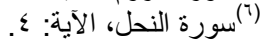


- تفسير القرآن الحكيم (تفسير المنار): محد رشيد بن علي رضا (المنوفى: عهبا(هـ)، (الهيئة المصرية العامة

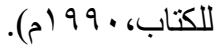

تفسير الماتريدي (تأويلات أهل السنة): محمد بن محمد بن محمود، أبو منصور الماتريدي (المتوفى: سبسآهـ)، تحقيق: د. د.

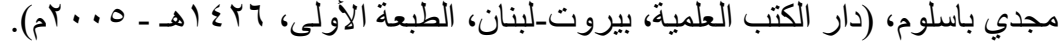

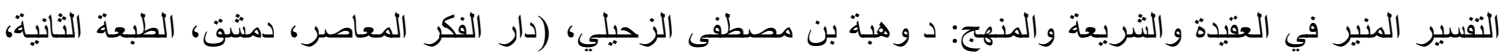

. (ه) (ه) (1)

تفسير مقاتل بن سليمان: أبو الحسن مقاتل بن سليمان بن بشير الأزدي البلخى (المتوفى: •010 إهـ)، تحقيق: عبد الله محمود

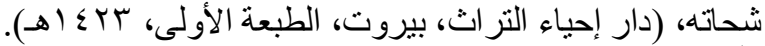

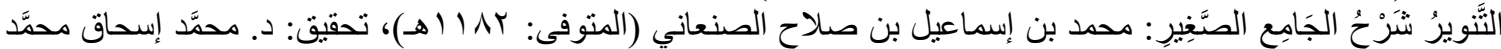

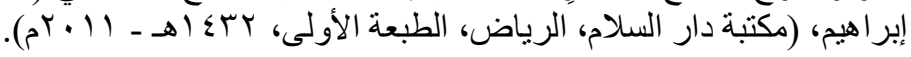

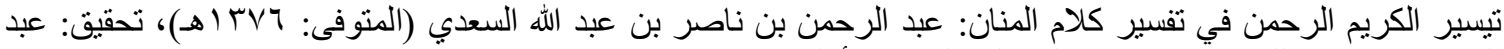

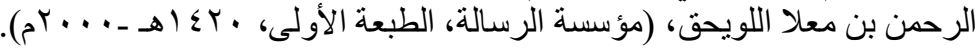

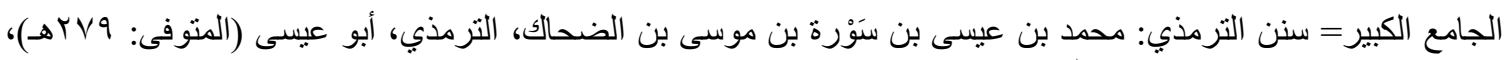

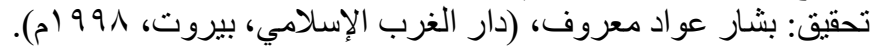

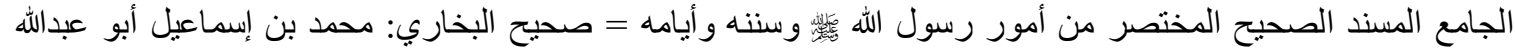

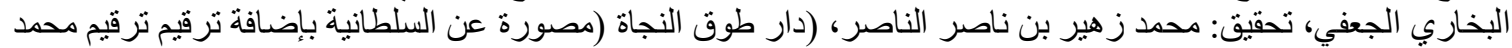

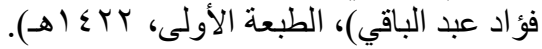
جسم الانسان في ارقام: د. محمد السقا عبد الأديد

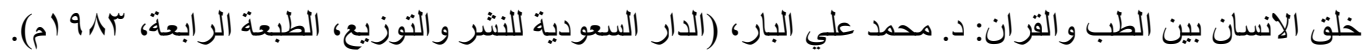
در اسات في النفس الانسانية: محمد قطب، (دار الثران الثروق).

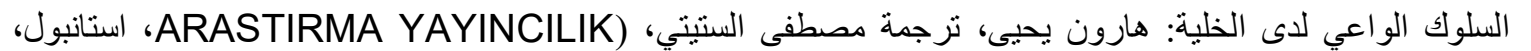
. ( $($...

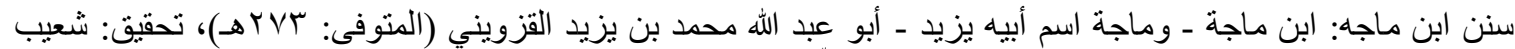

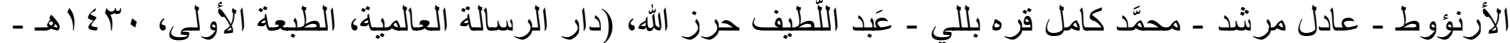

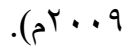

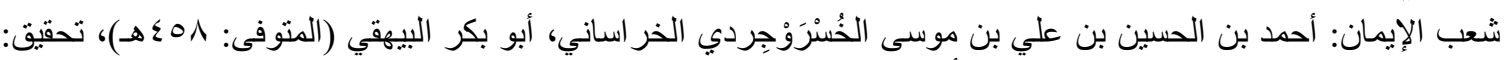

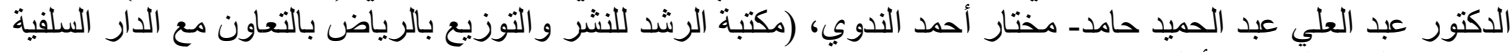

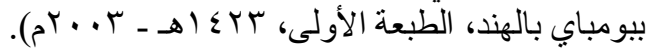

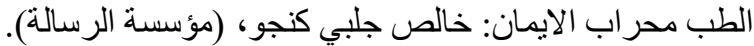

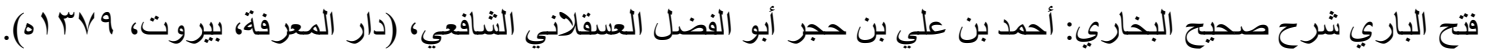

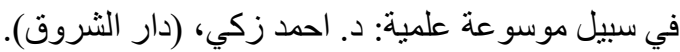

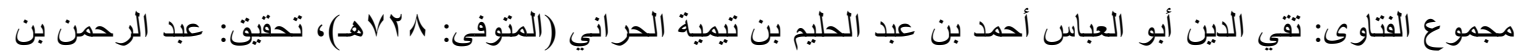

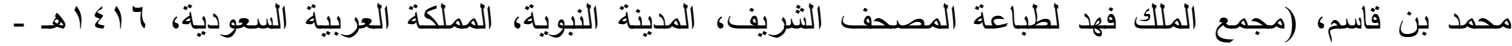
. (م) مدارج السالكين بين منازل إياك نعبد وإياك نستعين: محمد بن أبي بكر بن أيوب بن سعد شعس الدين ابن قيم الجوزية

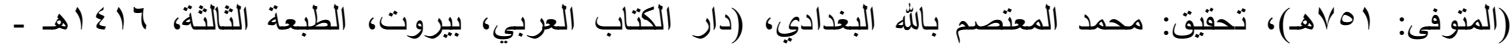

. (م) (م) (م)

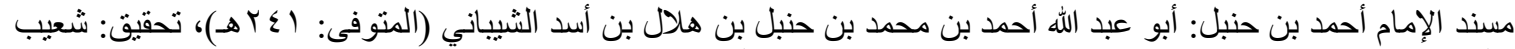

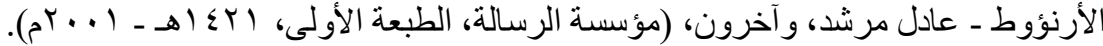

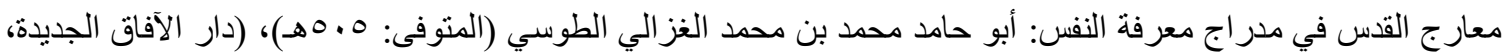

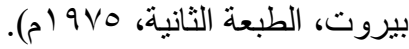

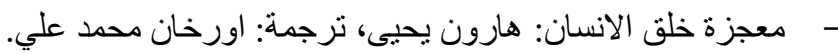

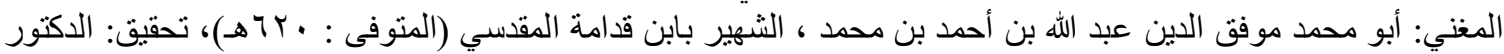

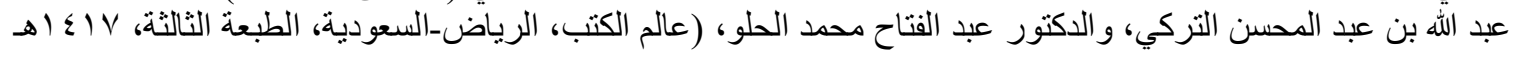

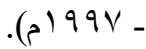
مفاتيح الغيب = التفسير الكبير: أبو عبد الله محمد بن عمر بن الحسن بن الحسين التيمي الرازي الملقب بفخر الدين الرازي خطيب الري (المتوفى: ج ـ 7 هـ)، (دار إحباء التراث العربي، بيروت، الطبعة الثالثة، ـ بـ (هـ). 


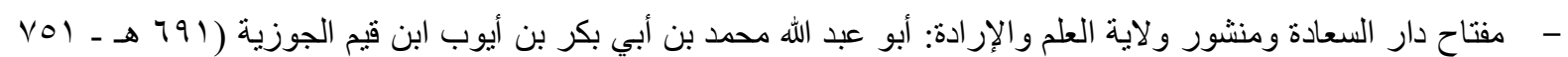

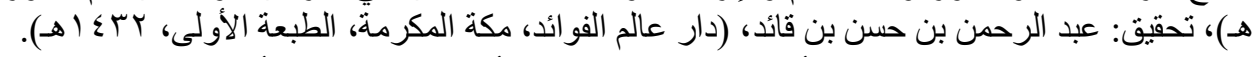

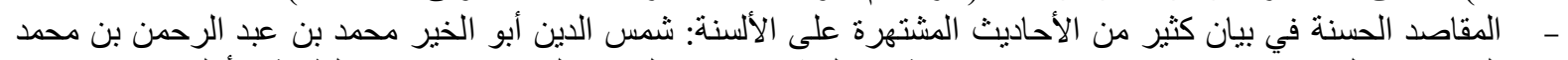

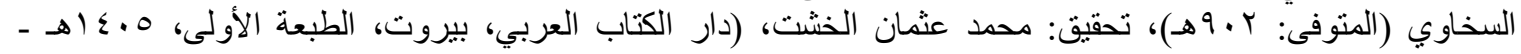

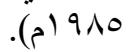

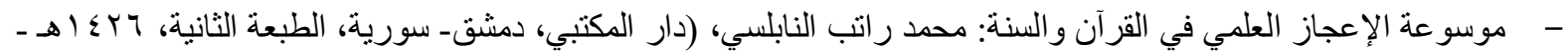

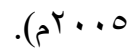

$$
\begin{aligned}
& \text { - الموسوعة القرآنية، خصائص السور: جعفر شرف الدين، تحقيق: عبد العزيز بن عثمان التويجزي، (دار التقريب بين }
\end{aligned}
$$

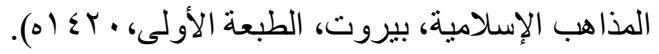

The greatness of God in the creation of man

God created man and made him his successor in the earth, and distinguished him from all creatures in the mind, and commanded the angels to prostrate to him, prostration of honor and glory, and prepared for him all that is in the heavens and the earth. Almighty God commanded man to think of his creation to realize that no partner with him, almighty said: \{And in yourselves do you not see.

The greatness of God in the creation of man can be demonstrated by:

God created Adam Abu al-Bishr from dust, Glory be to Him: \{And from His signs are that He created you from dust, and then, if you are human beings, you shall be spread.\}

Then he created his offspring from a sperm, God Almighty said: \{He created man from a sperm, so if it is an apparent adversity\} [An-Nahl:4]

God's ability to place this huge number of devices in the human body, each of them has its vital role and specific function in preserving human life, which operates according to a precise system determined by God. Scientists stand unable before The precise of this creation and the coherence of this huge construction the organic composition of a single cell is an issue that manages the head surprisingly, and in its psychological structure it is more surprising and sophisticated than its organic composition.

God created man in the best evaluation, and made him the best of the worlds, and he is amazing in his physical composition, and marvelous in his spiritual formation in the secrets of this soul, this consistency in the creation of its organs and their distribution, forms and functions, then its secrets in its reproduction, and that one cell has the characteristics of The human being, and each individual of this person is a world alone, and a special nature that is never repeated over the ages, nor has an analogy among all of its people, neither in its form and features, nor in its mind and perceptions, nor in its spirit and feelings, each individual has a special model, and a unique nature Not be repeated.

Keywords: Coherence, Sperm, Function, Creation, Features, Cell. 